Pre-print. This manuscript is being reviewed.

Please contact the first author for updates before citing.

\title{
Risk and protective factors of college students' psychological well-being during the COVID-19 pandemic: emotional stability, mental health, and household resources
}

Julia Moeller ${ }^{1}$, Luise von Keyserlingk², Marion Spengler ${ }^{3}$, Hanna Gaspard ${ }^{3,4}$, Hye Rin Lee ${ }^{2}$, Katsumi Yamaguchi-Pedroza ${ }^{2}$; Renzhe $\mathrm{Yu}^{2}$, Christian Fischer ${ }^{3}, \&$ Richard Arum $^{2}$

$$
\begin{gathered}
1=\text { Leipzig University, Germany } \\
2=\text { University of California, Irvine, U.S.A. } \\
3=\text { University of Tübingen, Germany } \\
4=\text { TU Dortmund University, Germany }
\end{gathered}
$$

Acknowledgements: We acknowledge the financial support for this research that was associated with a larger research project funded by the Andrew W. Mellon Foundation, \#1806-05902, and a Jacobs Foundation Early Career Research Fellowship to Julia Moeller.

Corresponding author: Julia Moeller, Leipzig University, julia.moeller@uni-leipzig.de 


\begin{abstract}
Colleges and universities have increasingly worried in recent decades about college students' wellbeing, with the COVID-19 pandemic aggravating these concerns. Our study provides empirical evidence of changes to undergraduate emotional sentiments and psychological wellbeing from before to after the onset of the pandemic. In addition, we explore whether certain risk factors (i.e., prior mental health impairments, trait emotional stability) and protective factors (i.e., subjective socioeconomic status, parental education, household resources) predicted students' emotions and their intra-individual changes due to the pandemic onset. We compared experience sampling method data from 120 students from before and after the pandemic onset, examining intra-individual trajectories.

There was only little change in students' emotions. Prior mental health impairment and trait emotional stability predicted students' emotions, averaged across time points, but not emotion changes. Few associations with emotions were found for subjective socioeconomic status and parental education, but study-related household-resources predicted levels and changes in emotions.
\end{abstract}

Keywords: COVID-19 pandemic, college students, psychological well-being, emotions, Experience Sampling Method, personality, intra-individual trajectories. 


\section{Risk and protective factors of college students' psychological well-being during the COVID-19 pandemic: emotional stability, mental health, and household resources}

\section{Introduction}

College and university concerns about undergraduate students' psychological well-being and mental health have increased in recent decades in the U.S. (e.g., Eisenberg et al., 2009; Lipson et al., 2018; Liu et al., 2019; Walters et al., 2018). This concern became heightened in the face of the COVID-19 pandemic, which affected the lives of the entire population, including the academic and social experiences of college students (e.g., Browning et al., 2020; Huckins et al., 2020). In addition to more general worries concerning health, personal income, and the economy, college students were also affected by the closures of campuses and the rapid shift to online course formats. Furthermore, many students were forced to move back in with their parents during a time of many restrictions and constraints, such as restricted contact to non-household members and home-schooled siblings. Simultaneously, social activities were drastically reduced as a consequence of social distancing.

With the increase in stressors came a decrease in psychological well-being and an increase in mental health issues. While already elevated in previous years (ACHA, 2018; LeViness et al., 2018; Lipson, Lattie, Eisenberg, 2018; NIMH, 2016; Pérez-Rojas et al. 2017; SAMHSA, 2017), negative emotions and mental health impairments have spiked among the overall U.S. population and college students in particular during the COVID-19 pandemic (CDC, 2020a, 2020b; Pfefferbaum \& North, 2020). Researchers relying on survey data have found that college students were more sedentary, anxious, and depressed during the COVID-19-affected term, compared to previous academic years, and their impaired mental health was related to 
maladaptive behavior, such as increased phone usage, decreased physical activity, and less active behavior (Charles et al. 2021; Huckins et al., 2020).

Individual coping with the COVID-19 pandemic is influenced by risk and protective factors (e.g., Sun et al., 2020; Browning et al., 2020; Sánchez Teruel, Robles Bello,Valencia Naranjo, 2021; Tang et al., 2020). This article focuses on risk and protective factors concerning university students' emotional coping with the COVID-19 pandemic, including prior mental health impairments, and the personality facet of low emotional stability (an aspect of neuroticism) as risk factors, as well as study-related household resources and the subjective socio-economic status (SES) as protective factors. We also tested whether the socioeconomic status predicted levels of and changes in emotions in this sample of college students. In contrast to most previous studies on risk and protective factors that relied solely on conventional crosssectional survey methodology (e.g., Browning et al., 2020), we assessed emotional sentiments with pre- and post surveys, but also in more immediate real-life situations and contexts. The latter allowed us to examine the intra-individual trajectories in emotions and may make these assessments more ecologically valid and less confounded with memory errors or other response biases (e.g., Takarangi, Garry, \& Loftus, 2006; Goetz et al., 2013).

More specifically, we used a unique study design that utilized both an experience sampling method (ESM) and pre- and post surveys between February and April 2020 to examine how the perceivable onset of the COVID-19 pandemic in the U.S. affected college students' campus and study activities, their emotions, and their psychological well-being. We expected that the impact of the pandemic-related stressors on students' emotions and well-being might be moderated by students' risk factors (low emotional stability; prior mental health impairment) and protective factors (access to study-related household resources and subjective SES). 


\subsection{The COVID-19 pandemic and its repercussions on student life, students' psychological well-being, and emotions}

The COVID-19 pandemic impacted many aspects of student life and well-being. This is of particular importance as students are typically regarded as a vulnerable population for mental health issues (Rubley, 2017). The core change to student life for many college students was the requirement to leave campus housing and the shift to emergency remote instruction. These repercussions of the pandemic may pose additional burdens on students' mental health (Liu, Pinder-Amaker, Hahm, \& Chen, 2020).

In particular, students who left campus housing might no longer have access to key resources for student success and well-being, such as a quiet place to study or in-person access to social support from classmates, student support staff, or faculty members. Initial empirical studies of the consequences of the pandemic indeed documented increases in college students' perceived stress, anxiety, and depressive symptoms after the onset of the COVID-19 pandemic (e.g., Charles et al., 2021, Wang et al., 2021, Husky et al., 2020, von Keyserlingk et al., in press, see also Table 1). Beyond that, students described concerns about potential health risks related to the pandemic for themselves, their families, and society (Cohen et al., 2020). With respect to stressors related to academic success, students were often concerned about their ability to continue with their studies to avoid degree completion delays (Hasan \& Bao, 2020).

It should be noted that psychological well-being and mental health are larger, multifacetted constructs (e.g., Ryff, 1989; Ryff, 2008; Ryff \& Singer, 2008; WHO, 2001; Gross \& Muñoz, 1995), of which only the emotional facets are examined in this article. Psychological well-being includes facets such as self-acceptance, positive relationships with others, autonomy, environmental mastery, personal growth, and purpose in life (e.g., Ryff \& Keyes, 1995). Mental 
health primarily refers to the absence of psychological disorders and symptoms thereof, but also includes many similar aspects, including working creatively and productively, maintaining positive relations to others, feeling comfortable when being alone, and feeling fulfillment (Gilmore, 1973; Gross \& Muñoz, 1995; Pfefferbaum \& North, 2020). In contrast, the indicators of mental health employed in this study mainly refer to the experience of high positive and low negative emotions.

\subsection{The impact of the pandemic on students is mitigated by risk and protective factors}

Since the pandemic brought myriad different stressors into the lives of most people, including college students, this was a time requiring extraordinary coping mechanisms. How individuals cope with stressors, such as the COVID-19 pandemic, differs between individuals and is influenced by individual and social risk and protective factors.

Among the empirically identified factors protecting students from harmful mental health impairments due to the COVID-19 pandemic were various coping strategies known to reduce stress levels, such as mindfulness, self-efficacy, and humor (e.g., Bendau et al. 2020; Savitsky, Findling, Ereli, Hendel, 2020; Sun et al., 2020), exercise (Chen et al., 2020), happiness (Zainal Badri \& Wan Mohd Yunus, 2021), social support, family income stability, and living in urban areas (Caoa et al., 2020), adaptability and positive emotions (Zhang et al., 2021), and being currently employed (Juchnowicz et al., 2021).

Among the risk factors aggravating the pandemic's effect on the participants' mental health were for instances COVID-19 related financial stress, stigma, perceived COVID-threat, and COVID-related worries, which predicted anxiety and depression, as well as female gender and COVID-19 prosocial behavior predicting anxiety (Sun, Goldberg, Lin, Qiao, \& Operario, 2020; Elmer et al. 2020), harmful emotion regulation strategies, such as emotion suppression or 
rumination (e.g., Bendau et al., 2020; Savitsky, et al., 2020). Female gender was also identified as a risk factor by Juchnowicz et al., (2021); Browning et al., (2020), Elmer et al. (2020), and Li, Fu, Fan, Zhu, \& Li (2021). The latter mentioned the further risk factors of studying for a Master degree, family suspected with COVID-19, having lost a loved one to COVID-19, decreased family income, online course characteristics (Little interaction, disturbed learning, difficulty in adaption), excessively collecting personal information, Family relatives' Intentional estrangement, suffering harassment, abuse or insult. The risk of contagion and having infected family members were found to be risk factors by Zainal Badri and Wan Mohd Yunus (2021) and well as Caoa et al. (2020). Elmer et al. (2020) further identified isolation in social networks, lack of interaction and emotional support, and physical isolation to be risk factors.

While the identification of risk and protective factors merely describes empirical associations, further theoretical models attempt to explain the underlying mechanisms driving these empirical relations. One such explanatory model is the demands-resources model, which suggests that demands are responsible for the negative mental health outcomes, including burnout symptoms and depression, while the resources needed to cope with demands drive positive and adaptive behavior (e.g., work or study engagement) and predict aspects of psychological well-being (e.g., Demerouti et al., 2001). In this sense, demands resemble either stressors or risk factors, while resources resemble protective factors.

Possible interactions between stressors and risk factors are described in further theoretical frameworks, the vulnerability-stress models, or diathesis-stress model (e.g., Chang et al., 2016; Colodro-Conde et al., 2018; Solberg et al., 1994). These models explain how mental health can be both a predictor and an outcome of the individual pathways that people take when coping with stressors such as a pandemic. The diathesis-stress model posits that individuals differ in their 
likelihood and severity to be affected by the same stressors, and this individual difference component is called vulnerability. Differences in vulnerability can for instance be due to personality-related, genetic, or social factors (Romanowicz et al., 2012; Solberg, Valdez, \& Villarreal, 1994; Van der Aa et al., 2009). More vulnerable individuals will tend to have a harder time coping with stressors than less vulnerable individuals. Several studies have applied diathesis-stress models to describe how interactions between vulnerability and the COVID-19pandemic-related stressors predicted mental health outcomes (e.g., Cox et al., 2020; Hong et al., 2020; Lynch et al., 2020; Raj et al., 2020). In line with this earlier research, we expect that prior mental health impairment may represent a vulnerability or risk factor affecting the ability to cope with an ongoing stressor, such as a pandemic. In the following sections, we introduce the risk and protective factors considered, and our hypotheses pertaining to them, in more detail.

\subsubsection{Trait emotional stability as a risk factor}

The effects of stressors on mental health are likely to vary depending on individuals' personality, especially their emotional stability. Emotional stability (also often labeled neuroticism) can be described as a personality trait characterized by the tendency of experiencing more depression, anxiety, and hostility for low levels of emotional stability (McCrae \& Costa, 1986). Emotional stability may affect a person's emotions during stressful times, such as a pandemic, in two main ways: First, low emotional stability is generally associated with increased levels of negative emotions, and second, emotional stability may aggravate (moderate) the effects of stressors on emotional and mental health outcomes.

Regarding the direct effects of emotional stability on emotions, low levels of emotional stability are correlated with a wide range of negative life outcomes, such as mental and physical health problems, low well-being (Kotov, Gamez, Schmidt, \& Watson, 2010; Lucas, 2018; 
Malouff, Thorsteinsson, \& Schutte, 2005), and also with level and variability of negative affect (Geukes et al., 2017; Kalokerinos et al., 2020; Kotov et al., 2010; Lucas, 2018; Malouff et al., 2005; Nestler, Hutteman, Küfner, \& Back, 2017; Wendt et al., 2020).

Furthermore, emotional stability is associated with the frequency and level of affective reactivity to stress (Hisler et al., 2020; DeHart, Krizan, \& Wright, 2020; Howland et al., 2017; Armeli, Feinn, \& Tennen, 2017; Bolger \& Schilling, 1991). In the university context, students with low emotional stability were found to react in more maladaptive ways to daily stressors, with more negative emotions and more pronounced mental health impairments (Felsten, 2004).

These studies suggest that students with low levels of emotional stability may be particularly vulnerable during stressful times such as the COVID-19 pandemic. On the one hand, their base level of negative emotions may be generally increased, and on the other hand they may react more sensitively to stressors.

\subsubsection{Psychological wellbeing and mental health as a mitigating factor}

Mental health is considered both an outcome of the ability to cope with stressors, and a predictor of it. For instance, both the demands-resources models of coping with stressors (e.g., Demerouti et al., 2001; McVicar, 2016) and the diathesis-stress model or vulnerability-stress model (e.g., Ingram et al., 2005) consider prior mental health as a resource and protective factor (or as the absence of a demand or risk factor) in encounters of stressors that may buffer against the negative consequences of the encountered stressors. According to these models, prior mental health impairment may exacerbate the impact of a stressor on people's emotions and well-being by additional stress and demands and by decreasing the resources available for coping strategies. At the same time, mental health impairments are considered outcomes of demands and stressors that balance individual coping mechanisms. 
Research on the relation between mental health and college students' coping during the COVID-19 pandemic has examined mental health mostly as an outcome (e.g., Hong et al., 2020; Savitsky et al., 2020; Sun et al., 2020), but occasionally also as a predictor (von Keyserlingk et al, in press).

\subsubsection{Socioeconomic background as a mitigating factor}

Financial insecurity is a well-known risk factor for psychological morbidity (Kopasker et al., 2018; Patel et al., 2018) and for health risks during the COVID-19 pandemic (Lassale, Gaye, Hamer, Gale, \& Batty, 2020). Scholars have expressed concerns that students and families with low-income backgrounds would experience even more psychological distress and stronger decreases in well-being during the COVID-19 pandemic (e.g., Purtle, 2020; Lederer et al., 2020). People with lower educational attainment experienced significantly more job and income losses during the COVID-19 pandemic (Daly et al., 2020), which can further exacerbate financial insecurity. The Student Experience in the Research University (SERU) Consortium administered a COVID-19 survey with more than 30,000 undergraduate students from nine research universities in the U.S., which found that students from low-income or working-class backgrounds experienced more financial hardships, food and housing insecurity, and had less access to appropriate study spaces and necessary technical tools for online learning compared to students from upper middle class or wealthy backgrounds (Soria \& Horgos, 2020). These stressors are likely to directly affect students' academic progress and performance, as well as their well-being. Data from the SERU survey further showed higher rates of generalized anxiety disorders and major depressive disorders among students of low-income and working-class backgrounds compared to students from higher social classes (Soria \& Horgos, 2020). 


\subsection{The present study}

Our theoretical framework integrates the afore-described research on various risk and protective factors in a joint model of college students' emotional coping with stressors related to the COVID-19 pandemic.

In this study, we use the distinction between protective and risk factors for the sake of organizing our hypotheses and predictors (see Figure 1). As assumed risk factors, we examine prior mental health impairments and trait emotional stability. As assumed protective factors, we will examine subjectively reported socio-economic status (SES), parental education, and studyrelated household resources. We distinguish between different indicators of socioeconomic resources and focus more precisely on socioeconomic indicators with direct relevance to academic engagement of college students, such as access to computers or study-materials.

In line with previous research, we assume that both risk and predictive factors can have direct effects on the outcomes of emotions and mental health, but also moderate the effects of the stressor (here: the pandemic) itself on these outcomes. This is in line with both the literature on various risk and protective factors in general (e.g., Magson et al., 2021), and the research on the specific risk and protective factors examined in this study (see e.g., the literature on stress reactivity mentioned above).

We refer to these models because together they help clarify why we consider mental health impairment both as a predictor and as an outcome of emotional stress reactivity. It should be noted that classification into risk and protective factors is arbitrary insofar as that all the constructs examined here are continuous variables with a pole representing risk (e.g., poverty, low emotional stability, impaired mental health, no access to study-related household resources) 
and an opposite pole representing protection (e.g., affluence, high emotional stability, good mental health, frequent access to study-related household resources).

\section{-----INSERT FIGURE 1 HERE-------}

This study extends the previous research by focusing on the longitudinal changes in insitu assessed emotions by examining the intra-individual trajectories. Most previous studies on risk and protective factors of mental health and psychological well-being among college students during the COVID-19 pandemic were cross-sectional (e.g., Sun et al., 2020; See Table S-1). The few available longitudinal either used inter-individual analyses (e.g., Huckins et al, 2020), which do not reliably tell how emotions change within persons (Kievit, Frankenhuis, Waldorp, \& Borsboom, 2013), or they used very few measurement time points (Savitsky, Findling, Ereli, Hendel, 2020b), whereas we used intensive longitudinal data of emotions being measured in the moments and contexts in which they occurred.

\subsection{Research Questions}

This study intends to examine four major research questions (RQs) related to positive emotions (i.e., engagement, joy, interest, and contentment) and negative emotions and affective states (i.e., anxiety, depressive feelings, hopelessness, boredom, feeling tired, feeling confused, and frustration). All hypotheses related to these research questions were pre-registered with the Open Science Framework (see Authors, 2020):

RQ1.1: How did students' levels of emotions change due to the arrival of the COVID-19 pandemic? 
Hypothesis 1.1: We expected that (a) students' mean levels of negative emotions would increase after the perceivable outbreak of the COVID-19 pandemic with its related campus closures and that (b) students' positive emotions decreased in the same time span.

RQ2: Were the mean-level changes in students' emotions during the pandemic associated with (a) students' prior mental health impairments and (b) emotional stability (risk factors)?

Hypothesis 2: For students' prior mental health impairments, we expected that students with stronger prior mental health impairments experienced larger increases in negative emotions, and larger decreases in positive emotions, compared to students with lower prior mental health impairment. For emotional stability, we expected that students with lower emotional stability experienced larger increases in the negative emotions, and larger decreases in the positive emotions, compared to students with higher emotional stability.

RQ3: Were the mean-level changes in students' emotions during the pandemic predicted by (a) students' socio-economic status and (b) study-related household resources (protective factors)?

Hypothesis 3: We expected that students of higher socioeconomic status experienced less increases in the negative emotions and less decreases in the positive emotions, compared to students with lower socioeconomic status. Furthermore, we expected that students who had insufficient access to a study place, internet connection, and resources for online classes during the 2020 Spring term reported larger increases in the negative emotions and a larger decrease in the positive emotions, compared to students who had sufficient access to these study-related household resources.

RQ4: Were the changes in students' emotions during the pandemic correlated to changes in their mental health? Was an increase in students' negative emotions (anxiety, depressive 
feelings, hopelessness, boredom, and frustration) during the pandemic associated with an increase in students' mental health impairment? Was a decrease in mean-levels of students' positive emotions (joy, interest, and contentment) during the pandemic associated with an increase in students' mental health impairment?

Hypothesis 4: We expected that students who showed a stronger increase of negative feelings and a stronger decrease of positive feelings in the ESM surveys also showed a stronger increase of mental health impairments in the post-test, compared to the pre-test.

\section{Methods}

\subsection{Sample and Data Collection}

The data were collected from February to April 2020 at a large public research university in Southern California. Students were recruited by several classroom announcements made in large lectures, fliers posted around campus, and online advertisements on social media. A convenience sample of 141 undergraduates consented to participate in the study. Forty-one percent of study participants majored in health and biological sciences, $15 \%$ in STEM majors, $33 \%$ in social and applied social sciences, $4 \%$ in arts and humanities, and $7 \%$ have not yet declared their major at the time of data collection. $73 \%$ of study participants self-identified as women. Study participants had diverse racial and ethnic backgrounds with 53\% Asian/Asian American, 27\% Hispanic or Latino/Latin American, 14\% White/European American, and 6\% other.

Data collection consisted of three parts: a pre-survey, a series of repeated experience sampling method surveys, and a post-survey. Participants were informed that they would receive 
a $\$ 50$ gift card at the end of the study. Participants did not receive reminders to complete notifications.

Directly after consenting to participate in this study, students completed the 20 question online pre-survey. In the last part of this survey, they were instructed to download the assessment app (ExpiWell) to participate in the experience sampling. Data collection with experience sampling continued over the course of seven weeks.

It should be noted that this study was a secondary data analysis. The data collection had been planned with other research questions in mind, and the onset of the pandemic surprised us during the ongoing study. Because one original goal of this study was to compare whether different surveying schedules (different lengths and intensities of the data collection) made a difference for the predictive value of ESM responses and the response rates, students were randomly assigned to one of three groups (Group A with $N=48$, Group B with $N=52$, and Group C with $N=41$ ) with distinct study durations (see S-5 in the supplemental online materials).

We used a signal-contingent sampling scheme with random time points for the ESM surveys. Each student was prompted to answer 50 ESM surveys (for the dates of these surveys, see Figure 3). We used data from ESM surveys that were sent to students in 2020 during observation window 1 (February 24 to March 6) and observation window 2 (March 30 to April 10). In between the two observation windows, the campus moved instruction online and urged students to leave campus housing on March 10, the World Health Organization declared a pandemic on March 11, President Trump declared a national emergency on March 17, California issued a statewide stay-at-home order on March 19, the campus announced its first confirmed COVID case on March 23 (for non-campus related dates, see AJMJ 2021). Once the 
questionnaire had been opened, it timed out and became unavailable if participants did not complete the full questionnaire within 30 minutes. Surveys were sent to students only on weekdays. The total number of completed ESM surveys (= sample size on the intra-individual within level) was 2,661. The average number of valid ESM responses per person was 21 (see Table 1).

The repeated ESM surveys included 15 questions (see S-4 in the supplementary online material). Students were randomly assigned to three groups with different beeping schedules. For detailed information about these groups and beeping schedules, see S-5 in the supplementary material. Lastly, students were asked to take a 19-question online post-test survey in April 2020 after completing all ESM surveys.

\subsection{Measures}

2.2.1 Pandemic onset. The COVID-19 pandemic was declared as such by the WHO on March 11, 2020. We created a binary variable indicating whether ESM data were collected in the week(s) before or after the official declaration of COVID-19 as a pandemic, which occurred on March 11, 2020, and the subsequent campus closures, which were announced on March 12, 2020 at this university. The binary time variable was coded 0 for before and 1 for after these two dates of March 11 and 12, 2020.

2.2.2 Emotions. Emotions were assessed in the experience sampling surveys. In every survey, students were asked to what extent they felt the following 11 emotions when they were beeped: engaged, interested, frustrated, confused, bored, anxious, depressed, tired, joyful, content, and hopeless. Students responded to these questions on a 5-point Likert scale (1 - not at all, 2 - a little, 3 - somewhat, 4 - more than some, 5 - extremely). In every survey, the questions about students' emotions were displayed in a random order. 
2.2.3 Personality trait emotional stability. Emotional stability was assessed in the presurvey with two items from the 10-item short scale NEO from Gosling \& Rentfrow (2003). Students were asked to rate how much they agreed with the following statements: I see myself as someone who (a) is relaxed, handles stress well, and (b) gets nervous easily. Students responded to these items on a 5-point Likert scale (1 - strongly disagree, 2 - disagree, 3 - neither agree nor disagree, 4 - agree, 5 - strongly agree).

2.2.4 Mental health impairment. Mental health impairment was assessed with 10 items based on the K10 screening instrument for non-specific psychological distress by Kessler et al. (2002). Students were asked how often in the past seven days they felt (a) "tired out for no good reason?”, (b) “nervous?”, (c) “so nervous that nothing could calm you down? ”, (d) "hopeless?”, (e) "restless or fidgety”, (f) “so restless you could not sit still?”, (g) “depressed?”, (h) "that everything was an effort?”, (i) “so sad that nothing could cheer you up?”, (j) “worthless?”. Students responded to these items on a 5-point Likert scale (1 - none of the time, 2 - a little of the time, 3 - some of the time, 4 - most of the time, 5 -all of the time). Please note: We measured instability (neuroticism), but use the reversed term emotional stability throughout the manuscript, because it is better known in the literature.

\subsubsection{Access to study-related household resources during the pandemic. Four} questions in the post-survey asked students if they had access to (a) a quiet study place without distractions, (b) a computer or other devices for course related tasks, (c) a stable internet connection, and (d) needed course material for online courses. Students responded to these items on a 7-point Likert scale (1 - never, 7 - all the time).

2.2.6 Self-reported socio-economic status. Subjective socioeconomic status was measured using one item of the MacArther scale on subjective social status (Adler et al., 2000). 
Students were asked to indicate their position on a 10 rung ladder that represents society. The top of the ladder represents people in society with a very high socioeconomic status, earn a lot of money and have a high education level, whereas the bottom of the ladder represents a very low socioeconomic status (Adler et al., 2000).

2.2.7 Parental education. Students reported the educational level of their parents, by selecting the highest obtained level of formal education of each of their parents or guardians of the following list: 'junior high, middle school or less', 'some high school', 'high school graduate/GED', 'some college', 'less than a bachelor's degree, including associate and technical degree', 'bachelor degree', and 'graduate degree of professional degree'. Based on these binary variables, we created one ordinal variable that indicates the highest obtained level of formal education of the students' parents that ranges from 1 - junior high, middle school or less to 7 graduate degree or professional degree.

\subsection{Analytical Methods}

Pre-registration:

The analyses for this study were pre-registered after data collection but prior to any analyses (please see Authors, 2020), using the templates for pre-registrations of ESM studies proposed by Kirtley et al. (2020).

Analyses:

To examine RQ1, the effect of the pandemic onset on students' emotion levels and their intra-individual changes (RQ1) were analyzed with multilevel random coefficient regression analyses (see Equation 1) in Mplus (version 7.4; Muthén \& Muthén, 1998-2015), with time 
points nested in individuals. The advantage of such models is that they allow both intercepts and slopes to vary across clusters, meaning across individuals.

The Mplus input files can be found as open code in the supplemental materials (see S-1). To examine whether positive and negative emotions changed as a function of the COVID-19 pandemic arriving in the US, we first created a binary variable indicating whether ESM data were collected in the week(s) before the official declaration of COVID-19 as a pandemic by the WHO (which occurred on March 11th 2020) and the subsequent campus closures (which were announced on March 12th, 2020 at this university). The binary time variable was coded 0 for before and 1 for after the official pandemic onset. We then estimated the intra-individual slope in the emotions by regressing the emotion on this binary time variable at the intra-individual (within-level) in a multilevel random coefficient regression analysis (see Equation 1). Because of the relatively small sample size on the person level (141 individuals), it was not possible to include all emotion outcomes in the same statistical model. Therefore, a separate model was estimated for each emotion.

Level 1: $\quad Y_{i j}=\beta_{0 j}+\beta_{1 j} \cdot X_{i j}+r_{i j}$ (EQ1)

Level 2: $\quad \beta_{0 j}=\gamma_{00}+u_{0 j}$

$$
\beta_{1 j}=\gamma_{10}+u_{1 j}
$$

On level 1 (= intra-individual), a random intercept $\left(\beta_{0 j}\right)$, a random slope $\left(\beta_{1 j}\right)$, and residual variance $\left(r_{i j}\right)$ are estimated. On level $2, \gamma_{00}$ represents the average intercept, across all individuals, and $\gamma_{10}$ the average slope, across all individuals, whereas $u_{0 j}$ represents the variance 
in the intercepts across all individuals, and $u_{1 j}$ the variance in the slopes across all individuals. Furthermore, the covariance between the average intercepts and slopes is estimated

To examine RQ2 and RQ3, all models examining the effects of the between-level predictors on emotion levels and emotion changes were analyzed with multilevel intercepts-andslopes-as-outcomes models. For that purpose, we added the respective risk factors in separate models as person-level (level 2) predictors and a cross-level moderator/interaction to the aforedescribed model in multilevel intercepts-and-slopes-as-outcomes models (see Equation 2). In addition to the parameters described in Equation 1 above, this model includes the Level-2 predictor $W_{j}$, on which both the intercepts and slopes are regressed. Each predictor was examined in a separate model, due to the relatively small sample of participants and large number of parameters that needed to be estimated.

Level 1: $\quad Y_{i j}=\beta_{0 j}+\beta_{1 j} \cdot X_{i j}+r_{i j}$ (EQ2)

Level 2:

$$
\begin{aligned}
& \beta_{0 j}=\gamma_{00}+\gamma_{01} \cdot W_{j}+u_{0 j} \\
& \beta_{1 j}=\gamma_{10}+\gamma_{10} \cdot W_{j}+u_{1 j}
\end{aligned}
$$

Figures of the models (Figures 2, 3, and 4) were created with Python. Since no standardized coefficients are estimated for the intended analyses (type $=$ twolevel random) in the program Mplus, we transformed all variables to a scale from 1 to 10 by using a variant of the POMP transformation (see Little, 2013). We chose this solution over the option to standardize all variables manually because of the various problems that can result from standardizing (intensive) longitudinal and nested data (e.g., Hamaker \& Grasman, 2915; Moeller, 2015). 
Missing data handling: We used Full Information Maximum Likelihood (FIML) estimations for missing data handling.

Intra-individual models of change: As psychological processes of change take place within individuals, intra-individual models are needed to understand these intra-individual processes (e.g., Molenaar, 2008; Reitzle \& Dietrich, 2019). For that purpose, we analyzed and plotted the trajectory from the first week(s) (pre-pandemic onset) of ESM data collection to the second (post pandemic onset) week of ESM data collection for each individual.

\section{Results}

\subsection{Linking the pandemic to changes in emotions (RQ1)}

To examine whether positive and negative emotions changed due to the arrival of the COVID-19 pandemic in the U.S., we regressed the emotions on the dichotomous pandemiconset-variable in the intra-individual (within-level) in a multilevel random coefficient regression analysis (see Equation 1).

The results of these models are summarized in Table 1. The slopes indicate whether an emotion increased or decreased from the first week of data collection (before the official pandemic onset) to the second week of data collection (after the pandemic onset). Only two emotions showed a significant change, and none of them was in the expected directions (Table 2). There was a significant increase in engagement $(B=.362 ; \mathrm{p}<0.05)$ and a decrease in tiredness $(B=-.528, \mathrm{p}<0.05)$. Thus, we can reject our hypotheses that the declaration of COVID-19 as a pandemic in the U.S. and the subsequent campus closures lead to an observable increase in students' momentary negative emotions and decrease in momentary positive emotions. 
------INSERT HERE Table 1----

The variance of the slope indicates inter-individual differences in regard to the intraindividual trajectories in emotions from before to after the pandemic onset. Figure 2 illustrates this inter-individual heterogeneity in regard to intra-individual changes in emotions, which shows increases for some individuals and decreases for others in each of the eleven examined emotions. For this figure, we first calculated each person's average for time 1 (before the pandemic onset) and time 2 (after pandemic onset) and then plotted the intra-individual trajectories as blue lines, and the change from the inter-individual average (red dot) from time 1 to time 2 as red horizontal line.

-------INSERT FIGURE 2 HERE-------

\subsection{Linking changes in emotions to risk factors (RQ 2}

Next, we examined whether the risk factors of prior mental health impairment and trait emotional stability predicted changes in emotions from before to after the pandemic onset.

\section{------INSERT HERE Table 2------}

As expected, prior mental health impairments (see Table 2) were a significant negative predictor of all positive emotion mean scores $(-.237 \leq B \leq-.129)$. Likewise in line with our hypotheses, prior mental health impairments significantly positively predicted all negative emotion mean scores $(.146 \leq B \leq .350)$. In contrast, prior mental health impairments predicted the pre-to-post pandemic onset change in only one emotion: feeling content $(B=-.119 ; p=.027)$.

\section{------INSERT HERE Table 3------}

As expected, low emotional stability (see Table 3 ) was a negative significant predictor of various positive emotion mean scores, namely feeling interested $(B=-.088 ; p=.045)$, feeling 
engaged $(B=-.102 ; p=.021)$, feeling joyful $(B=-.185 ; p=.003)$, and feeling content $(B=-.198$; $p=.002$ ). Likewise in line with our hypotheses, low emotional stability was a positive significant predictor of various negative emotion mean scores, namely feeling anxious $(B=.158 ; p=.001)$, feeling frustrated $(B=.094, p=.028)$, feeling depressed $(B=.087 ; p=.012)$, feeling hopeless $(B$ $=.115 ; p=.003)$, and feeling tired $(B=.169 ; p=.004)$. In addition, low emotional stability predicted the pre-to-post pandemic onset change in feeling anxious negatively $(B=-.092 ; p=$ $.019)$ and the change in confusion positively $(B=.087 ; p=.022)$.

\subsection{Linking changes in emotions to protective factors (RQ3)}

\subsubsection{Socioeconomic status}

\section{------INSERT HERE Table 4------}

The subjectively perceived socioeconomic status predicted the mean score of only one emotion, contentment $(B=.227 ; p=.003)$ and the intra-individual change in only one, other, emotion: feeling joyful $(B=.151 ; p=.009$ please see Table 4$)$. In our pre-registered hypotheses, we had expected the SES to be positively associated with the changes and intercepts of positive emotions and to be negatively associated with the changes and intercepts of negative emotions.

\subsubsection{Parental education}

\section{------INSERT HERE Table 5------}

Parents' education predicted the mean score of feeling anxious $(B=.176 ; p=.000)$, frustrated $(B=.125 ; p=.001)$, depressed $(B=.134 ; p=.000)$, hopeless $(B=.143 ; p=.000)$ and feeling tired $(B=.142 ; p=.004)$, as well as the intra-individual change in two other emotions: feeling bored $(B=.087 ; p=.006)$ and feeling interested $(B=.089 ; p=.015$ please see Table 5$)$.

\subsubsection{Study-related household resources}

------INSERT HERE Table 6------ 
The access to study materials predicted the mean scores of feeling frustrated $(B=-.094 ; p$ $=.029)$, feeling hopeless $(B=-.097 ; p=.046)$, feeling tired $(B=-.136 ; p=.020)$, and feeling confused $(B=-.097 ; p=.033$ please see Table 6$)$. Six emotions showed a change from before to after the pandemic onset that depended significantly on the access to a study place: feeling anxious $(B=-.211 ; p=.004)$, feeling frustrated $(B=-.152 ; p=.005)$, feeling depressed $(B=$ $.133 ; \mathrm{p}=.012)$, feeling hopeless $(B=-.147 ; p=.027)$, feeling joyful $(B=.083 ; p=.033)$, and feeling content $(B=.104 ; p=.020)$.

------INSERT HERE Table 7------

The access to a stable internet connection predicted the mean scores of feeling frustrated $(B=-.097 ; p=.024)$, feeling hopeless $(B=-.092 ; p=.020)$, feeling tired $(B=-.231 ; p=.001)$, and feeling confused $(B=-.102 ; p=.019 ;$ please see Table 7$)$. Three emotions showed a change from before to after the pandemic onset that depended significantly on the access to a study place: feeling bored $(B=-.124 ; p=.004)$, feeling interested $(B=.116 ; p=.027)$, and feeling joyful $(B=.154 ; p=.002)$.

------INSERT HERE Table 8------

The access to a computer or other working device predicted the mean scores of feeling frustrated $(B=-.177 ; p=.015)$, feeling hopeless $(B=-.122 ; p=.041)$, feeling tired $(B=-.228 ; p$ $=.005)$, feeling bored $(B=-.174 ; p=.004)$, and feeling confused $(B=-.182 ; p=.042 ;$ please see Table 8). Two emotions showed a change from before to after the pandemic onset that depended on the access to a computer or other working device: feeling anxious $(B=.144 ; p=.021)$ and feeling tired $(B=.117 ; p=.031)$. 
The access to a study place allowing the student to focus on their coursework predicted the mean scores of feeling frustrated $(B=-.093 ; p=.008)$, feeling hopeless $(B=-.057 ; p=.034)$, feeling tired $(B=-.091 ; p=.036)$, feeling joyful $(B=.122 ; p=.005)$, and feeling content $(B=$ $.130 ; p=.005$; please see Table 9). Three emotions showed a change from before to after the pandemic onset that depended on the access to a study place: feeling frustrated $(B=-.079 ; p=$ $.039)$, depressed $(B=-.106 ; p=.002)$, and hopeless $(B=-.093 ; p=.028)$.

\subsection{Linking changes in emotions to changes in mental health impairment (RQ4)}

As expected, changes in emotions from the first to the second week of ESM data collections were associated with changes in mental health in the pre- versus post-test (see Table 10). The intra-individual slopes of all negative feelings, except for feeling tired, were positively predicted by the change in mental health impairment (difference score post- minus pre-test). This means that an increase in mental health impairment was positively associated with increases in the negative emotions (feeling anxious, frustrated, hopeless, confused, bored). Changes in three positive emotions were unrelated to changes in mental health impairment. At first sight, it may appear as of changes in interest were positively associated with changes in mental health, however, this finding is only significant if the one-sided, not if the two-sided p-value is considered, and since it is an unexpected finding, the correct p-value to consider would be the two-tailed score. Thus, in sum, changes in the positive emotions can be considered all unrelated to changes in mental health impairment. Similarly, the mean scores (intercepts) of all emotions, positive as negative, were unrelated to the change score of mental health impairment. 


\section{Discussion}

This study examined the impact of the COVID-19 pandemic on college students' positive and negative emotions by comparing ESM data before and after the onset. In addition to average effects, we examined whether the inter-individual variance in the intra-individual trajectories were explained by a comprehensive set of risk factors and protective factors, including trait emotional stability, prior mental health impairments, socioeconomic status, and study-related household resources. Overall, the three main findings of this study are as follows:

First, there were surprisingly few changes in student emotions from before and after the onset of the pandemic. Notably, we unexpectedly found that students' tiredness decreased while their engagement increased from before to after the pandemic onset.

Second, the risk factors of prior mental health impairments and low trait emotional stability predicted the mean scores in emotions (i.e., a student's average anxiety across all measurement time points) in the expected directions (positive relations with negative emotions and negative relations to positive emotions). However, the intra-individual change in emotions (stress reactivity) was not affected by these predictors.

Third, socioeconomic status only positively predicted the mean score of a single emotion: feeling content, and the intra-individual change in feeling joyful. The protective factors with the most striking relations to students' emotions were study-related household resources, particularly access to study materials. Access to study materials predicted the intra-individual change in emotions more than their mean scores, in all the expected directions (positive effect on positive emotions' slopes and negative effects on negative emotions' slopes). Hence, immediate change in emotions in the first weeks after the onset of the pandemic was related to access to 
specific study-related resources, rather than to broader measures of students' socioeconomic background.

\subsection{Theoretical Implications}

Most of the previous studies on risk and protective factors in regard to emotional coping with the COVID-19 pandemic rely on cross-sectional self-reports, although a few (e.g., Huckins et al., 2020) examined emotional coping with similar intensive longitudinal data as this study does.

Our study suggests that the onset of the pandemic did not directly translate into an immediate decrease in emotional wellbeing for students. This contrasts other studies that found that anxiety and depression increased for college students both in comparison to earlier weeks in the study term and a previous term (e.g., Huckins et al., 2020). These differences between our findings and Huckins et al. (2020) may reflect differences between the geographical locations and student populations. Huckins et al. (2020) was situated at Dartmouth, a highly selective private Ivy-League University which is located in the U.S. East Coast. In contrast, this study is situated in the U.S. West Coast at a large public university that is federally designated as a Asian American and Native American Pacific Islander-Serving Institution (AANAPISI) and as a Hispanic-Serving Institution (HSI). Another plausible reason for these differences between both studies is methodological: the sample size of momentary measures was much larger in the Huckins et al. (2020) study, with 113,864 observations for anxiety and 20,323 observations for depression, compared to our 2,995 ESM observations. With such large sample sizes even the smallest differences may become statistically significant, and Huckins et al. (2020) report relatively small mean score differences in both anxiety and depression. Also, Huckins et al. (2020) compared the anxiety and depression values from a previous term with those from the 
COVID-19 term, contrasting our comparison from weeks before to after the pandemic onset within the COVID-19 term. This difference is potentially larger than the difference that we examined, from earlier weeks in the term to later weeks, because in the prior comparison term reported by Huckins et al., anxiety and depression decreased in March and April, compared to earlier weeks, while they increased in March and April during the COVID-19 term. Thus, the difference between the decreased values in the comparison term with the increased values in the COVID-19 term is larger than the difference between the earlier weeks in the term and the last weeks in the term.

Overall, our results support research that suggests emotional granularity (e.g., Lange et al., 2020) as the effects of the predictors on emotions mean scores and trajectories differ with respect to specific emotions. Predictors affected different emotions in unique ways. This is consistent with prior research. For instance, our finding that students reported tiredness as their strongest emotion corresponds with other studies examining affective experience in educational settings, such as Moeller, Brackett, et al., (2020), who also reported this pattern for high school settings. It has often been discussed that sleep deprivation is a serious risk to the psychological and emotional wellbeing of college students and young adults (National Sleep Foundation, 2006; Owens, \& Adolescent Sleep Working Group, 2014; Owens et al., 2010). The decrease from before to after the pandemic onset in tiredness may have protected some students from some of their usual stress, which may have buffered expected negative effects of the pandemic onset on college students' emotions.

The finding that trait emotional stability was only predictive for mean scores but not intra-individual changes in emotions does not support theories assuming that trait emotional stability (or neuroticism) affect both emotional sentiments and stress reactivity (e.g., Bolger \& 
Schilling, 1991). This may be due to students not having experienced sufficient stress for such individual differences in the stress response to become observable.

From a methodological perspective, our finding that mental health and trait emotional stability (i.e., neuroticism)measures predicted the mean scores of students positive and negative emotions in expected directions may be considered as an indicator of the measures' validity. The items capturing mental health impairment and trait emotional stability strongly refer to experienced emotions, so that these relations between predictors and ESM emotion measures are not surprising and may even be judged as tautological. Nevertheless, finding covariances between the state and trait measures referring to negative emotional experiences yields valuable insights, because it is theoretically possible and empirically found sometimes that state and trait measures do not capture the same phenomena and therefore fail to function in similar ways (e.g., Goetz et al., 2013).

This study has several implications for educational administrators and public health professionals in the sector. Recently, many scholars expressed concerns that students with lowincome backgrounds would experience even more psychological distress and stronger decreases in well-being during the COVID-19 pandemic (e.g., Purtle, 2020; Lederer et al., 2020). Our results showed that students from lower-income backgrounds did not suffer from larger increases of negative emotions overall. Instead, we found more narrowly evidence that specific studyrelated household resources (e.g., access to a quiet study place and study materials) were relevant predictors of college students' emotional well- and ill-being after the onset of the pandemic and the related shift to emergency remote learning. These findings provide actionable insights on how to support students coping with stressors: in addition to traditional tools, such as counseling, or mental health interventions (see e.g., Seppälä et al., 2020), interventions for college students 
could focus on mitigating the most acute access limitations to study-related resources, in the hope not only to improve the study behavior itself, but also improve college students' psychological well-being.

\subsection{Limitations}

This study relied on a quasi-experimental design, with all the limitations to causal interpretations that this entails. Moreover, when planning the study, we did not anticipate such a quasi-experiment (or pandemic) to happen. In this sense, this was a secondary analysis of data that were collected originally with other research questions in mind. Therefore, we did not include predictors that in retrospect would be potentially useful for the understanding of coping in the face of a pandemic, such as health-related demands and resources. Because of these reasons, we were only able to pre-register this study after the data collection, but before the data analysis.

In order to examine the long-term-effects of the pandemic, it would have been desirable to have data from a longer period of ESM data collection, such as the week-to-week reports across an entire term as reported by Huckins et al. (2020). As stated above, additional comparison data from Spring terms in the years before (or after) the pandemic would have been needed to disentangle the usual emotional changes over the course of a typical term from those due to the pandemic.

For all analyses concerning the inter-individual (between-) level, the sample size for this study was relatively small (141 individuals). This is due to the fact that this was originally planned to serve as a pilot study on the impact of different surveying schedules. This small number of individuals may affect the replicability of the findings in the following ways: , We know that correlation coefficients only stabilize in samples of about 250 or more individuals 
(Schönbrodt \& Perugini, 2013). In particular, our sample may have been too small to discover any systematic inter-individual differences in emotions as a function of subjectiveSES. As the violin plots (see Figure 4 and Figure 5) indicate, there were very few individuals on either pole of the response scale of the subjective SES question, and a larger sample with enough individuals in each subjective SES group would be needed to examine this relationship.

The assignment of mental health impairment and trait emotional stability to risk factors and socioeconomic indicators as protective factors is arbitrary insofar as all these variables are continuous, with a negative and a positive pole. The presence of mental health can be considered a protective factor while its absence is considered a risk factor. Vice versa, poverty could be considered a risk factor, but the opposite, affluence, a protective factor. Thus, future studies could aim to find out which exact study-related resources can be affected with which measures during such states of emergency to make sure students have what they need to study and feel well. Another research question for future studies is whether study-related demands affect students' psychological well-being in similar ways as study-related resources, and whether the demands-resources models of engagement and burnout (e.g., Demerouti et al., 2001; McVicar, 2016) may contribute to the understanding of best support for students during a pandemic.

The time window during which we were able to examine the changes in students' emotions was very early into the pandemic, and rather short. At that point of time, the potential stressors were still less pronounced than during later phases of the pandemic. For example, local prevalence rates were rather low, younger people were thought to be relatively safe, and the economic impacts were muted. This may have affected both the extent to which changes in emotions were observable, and the potentially disproportionate impacts of pandemic-related by personal risk and protective factors. 


\subsection{Conclusion}

Using ESM data about college students' emotions in the weeks before and after the onset of the COVID-19 pandemic, we did not observe the expected decrease in positive emotions nor the expected increase in negative emotions on average. Among a comprehensive set of potential risk and protective factors, including prior mental health impairment, trait emotional stability as well as subjective socioeconomic status and familial resources, study-related household resources emerged as the most consistent predictor of changes in students' emotions. These study-related resources have been most proximally related to students' well-being during the shift to remote instruction. These findings provide actionable insights on how to support students coping with online learning in times of a pandemic: providing practical support with respect to study-related resources and being mindful of students' limitations in access to these resources. 


\section{References}

Adler, N. E., Epel, E. S., Castellazzo, G., \& Ickovics, J. R. (2000). Relationship of subjective and objective social status with psychological and physiological functioning: Preliminary data in healthy white women. Health Psychology, 19(6), 586-594.

American College Health Association. (2018). American College Health Association-National College Health Assessment II: Reference Group Executive Summary Fall 2018. https://www.acha.org/documents/ncha/NCHA-

\section{Fall 2018 Reference Group Executive Summary.pdf}

American Journal of Managed Care Staff, “A Timeline of COVID-19 Developments in 2020,” American Journal of Managed Care (January 1, 2021). https://www.ajmc.com/view/atimeline-of-covid19-developments-in-2020

Armstrong, P. I., \& Anthoney, S. F. (2009). Personality facets and RIASEC interests: An integrated model. Journal of Vocational Behavior, 75(3), 346-359. https://doi.org/10.1016/j.jvb.2009.05.004

Authors et al. (2020, December 10). Pre-registration: College students' emotions during the COVID-19 pandemic: The role of emotional stability, mental health, and household resources.

Babore, A., Lombardi, L., Viceconti, M. L., Pignataro, S., Marino, V., Crudele, M., Candelori, C., Bramanti, S. M., \& Trumello, C. (2020). Psychological effects of the COVID-2019 pandemic: Perceived stress and coping strategies among healthcare professionals. Psychiatry Research, 293, 113366. https://doi.org/10.1016/j.psychres.2020.113366

Beauducel, A., Liepmann, D., Felfe, J., \& Nettelnstroth, W. (2007). The impact of different measurement models for fluid and crystallized intelligence on the correlation with 
personality traits. European Journal of Psychological Assessment, 23, 71-78. https://doi.org/10.1027/1015-5759.23.2.71

Bendau, A., Plag, J., Kunas, S., Wyka, S., Ströhle, A., \& Petzold, M. B. (2021). Longitudinal changes in anxiety and psychological distress, and associated risk and protective factors during the first three months of the COVID-19 pandemic in Germany. Brain and Behavior, 11(2), e01964. https://doi.org/10.1002/brb3.1964

Bolger, N., \& Schilling, E. A. (1991). Personality and the problems of everyday life: The role of neuroticism in exposure and reactivity to daily stressors. Journal of Personality, 59, 355386. https://doi.org/10.1111/j.1467-6494.1991.tb00253.x

Bipp, T., Steinmayr, R., \& Spinath, B. (2008). Personality and achievement motivation:

Relationship among big five domains and facet scales, achievement goals, and intelligence. Personality and Individual Differences, 44, 1454-1464. https://doi.org/10.1016/j.paid.2008.01.001

Browning, M. H., Larson, L. R., Sharaievska, I., Rigolon, A., McAnirlin, O., Mullenbach, L., ... \& Alvarez, H. O. (2021). Psychological impacts from COVID-19 among university students: Risk factors across seven states in the United States. PloS one, 16(1), e0245327. Cacioppo, J. T., \& Berntson, G. G. (1994). Relationship between attitudes and evaluative space: A critical review, with emphasis on the separa- bility of positive and negative substrates. Psychological Bulletin, 115, 401-423. http://dx.doi.org/10.1037/0033-2909.115.3.401

Cao, W., Fang, Z., Hou, G., Han, M., Xu, X., Dong, J., \& Zheng, J. (2020). The psychological impact of the COVID-19 epidemic on college students in China. Psychiatry research, 287, 112934. 
Center for Disease Control and Prevention. (2020a). Mental health: Household Pulse Survey. https://www.cdc.gov/nchs/covid19/pulse/mental-health.htm

Center for Disease Control and Prevention. (2020b). Early release of selected mental health estimates based on data from the January-June 2019 National Health Interview Survey. https://www.cdc.gov/nchs/data/nhis/earlyrelease/ERmentalhealth-508.pdf

Chang, E. C., Yu, T., Chang, O. D., \& Hirsch, J. K. (2016). Hope and trauma: Examining a diathesis-stress model in predicting depressive and anxious symptoms in college students. Personality and Individual Differences, 96, 52-54. https://doi.org/10.1016/j.paid.2016.02.060

Chen, R. N., Liang, S. W., Peng, Y., Li, X. G., Chen, J. B., Tang, S. Y., \& Zhao, J. B. (2020). Mental health status and change in living rhythms among college students in China during the COVID-19 pandemic: A large-scale survey. Journal of Psychosomatic Research, 137, 110219.

Colodro-Conde, L., Couvy-Duchesne, B., Zhu, G., Coventry, W. L., Byrne, E. M., Gordon, S., Wright, M. J., Montgomery, G. W., Madden, P. a. F., Major Depressive Disorder Working Group of the Psychiatric Genomics Consortium, Ripke, S., Eaves, L. J., Heath, A. C., Wray, N. R., Medland, S. E., \& Martin, N. G. (2018). A direct test of the diathesisstress model for depression. Molecular Psychiatry, 23(7), 1590-1596. https://doi.org/10.1038/mp.2017.130

Conversano, C., Di Giuseppe, M., Miccoli, M., Ciacchini, R., Gemignani, A., \& Orrù, G. (2020). Mindfulness, age and gender as protective factors against psychological distress during Covid-19 pandemic. Frontiers in Psychology, 11, 1900. 
Cox, R. C., Jessup, S. C., Luber, M. J., \& Olatunji, B. O. (2020). Pre-pandemic disgust proneness predicts increased coronavirus anxiety and safety behaviors: Evidence for a diathesisstress model. Journal of Anxiety Disorders, 76, 102315. https://doi.org/10.1016/j.janxdis.2020.102315

Davidson, R. J. (1998). Affective style and affective disorders: Perspectives from affective neuroscience. Cognition and Emotion, 12, 307-330. http://dx.doi.org/10.1080/026999398379628

Demerouti, E., Bakker, A. B., Nachreiner, F., \& Schaufeli, W. B. (2001). The job demandsresources model of burnout. Journal of Applied Psychology, 86(3), 499-512. https://doi.org/10.1037/0021-9010.86.3.499

Diener, E., \& Emmons, R. A. (1984). The independence of positive and negative affect. Journal of Personality and Social Psychology, 47, 1105-1117. http://dx.doi.org/10.1037/0022-3514.47.5.1105

Eisenberg, D., Golberstein, E., \& Hunt, J. B. (2009). Mental health and academic success in college. The B.E. Journal Economic Analysis \& Policy, 9(1). https://doi.org/10.2202/1935-1682.2191

Elmer, T., Mepham, K., \& Stadtfeld, C. (2020). Students under lockdown: Comparisons of students' social networks and mental health before and during the COVID-19 crisis in Switzerland. Plos one, 15(7), e0236337.

Felsten, G. (2004). Stress reactivity and vulnerability to depressed mood in college students. Personality and Individual Differences, 36(4), 789-800.

Frijda, N. (1986). The emotions. New York, NY: Cambridge University Press. 
Geukes, K., Nestler, S., Hutteman, R., Küfner, A. C., \& Back, M. D. (2017). Trait personality and state variability: Predicting individual differences in withinand cross-context fluctuations in affect, self-evaluations, and behavior in everyday life. Journal of Research in Personality, 69, 124-138. https://doi.org/10.1016/j.jrp.2016.06.003

Guo, Y., Cheng, C., Zeng, Y., Li, Y., Zhu, M., Yang, W., Xu, H., Li, X., Leng, J., Monroe-Wise, A., \& Wu, S. (2020). Mental health disorders and associated risk factors in quarantined adults during the COVID-19 outbreak in China: Cross-sectional study. Journal of Medical Internet Research, 22(8), e20328. https://doi.org/10.2196/20328

Hamaker, E.L. \& Grasman, R.P.P.P. (2015). To center or not to center? Investigating inertia with a multilevel autoregressive model. Frontiers in Psychology, 5, 1492. https://doi.org/10.3389/fpsyg.2014.01492

Hasan, N., \& Bao, Y. (2020). Impact of “e-Learning crack-up” perception on psychological distress among college students during COVID-19 pandemic: A mediating role of "fear of academic year loss". Children and Youth Services Review, 118, 105355.

Hisler, G. C., DeHart, T., Krizan, Z., \& Wright, A. G. (2020). Neuroticism as the intensity, reactivity, and variability in day-to-day affect. Journal of Research in Personality, 87, 103964. https://doi.org/10.1016/j.jrp.2020.103964

Hong, W., Liu, R. D., Ding, Y., Fu, X., Zhen, R., \& Sheng, X. (2020). Social media exposure and college students' mental health during the outbreak of CoViD-19: the mediating role of rumination and the moderating role of mindfulness. Cyberpsychology, Behavior, and Social Networking. http://doi.org/10.1089/cyber.2020.0387 
Howland, M., Armeli, S., Feinn, R., \& Tennen, H. (2017). Daily emotional stress reactivity in emerging adulthood: Temporal stability and its predictors. Anxiety, Stress, \& Coping, 30, 121-132. https://doi.org/10.1080/10615806.2016.1228904

Huckins, J. F., DaSilva, A. W., Wang, W., Hedlund, E., Rogers, C., Nepal, S. K., Wu, J., Obuchi, M., Murphy, E. I., Meyer, M. L., Wagner, D. D., Holtzheimer, P. E., \& Campbell, A. T. (2020). Mental health and behavior of college students during the early phases of the COVID-19 pandemic: Longitudinal smartphone and ecological momentary assessment study. Journal of Medical Internet Research, 22(6), e20185.

Ingram, R. E., \& Luxton, D. D. (2005). Vulnerability-Stress Models. In B.L. Hankin \& J. R. Z. Abela (Eds.), Development of psychopathology: A vulnerability stress perspective (pp. 32-46). Sage Publications Inc.

Juchnowicz, D., Baj, J., Forma, A., Karakuła, K., Sitarz, E., Bogucki, J., \& KarakulaJuchnowicz, H. (2021). The Outbreak of SARS-CoV-2 Pandemic and the Well-Being of Polish Students: The Risk Factors of the Emotional Distress during COVID-19 Lockdown. Journal of Clinical Medicine, 10(5), 944.

Kalokerinos, E. K., Murphy, S. C., Koval, P., Bailen, N. H., Crombez, G., Hollenstein, T., \& Bastian, B. (2020). Neuroticism may not reflect emotional variability. Proceedings of the National Academy of Sciences, 117, 9270-9276. https://doi.org/10.1073/pnas.1919934117

Kashdan, T. B., Barrett, L. F., \& McKnight, P. E. (2015). Unpacking emotion differentiation: Transforming unpleasant experience by perceiving distinctions in negativity. Current Directions in Psychological Science, 24(1), 10-16. 
Kievit, R., Frankenhuis, W. E., Waldorp, L., \& Borsboom, D. (2013). Simpson's paradox in psychological science: a practical guide. Frontiers in psychology, 4, 513.

Kirtley, O. J., Lafit, G., Achterhof, R., Hiekkaranta, A. P., \& Myin-Germeys, I. (2020, March 12). A template and tutorial for (pre-)registration of studies using Experience Sampling Methods (ESM). https://doi.org/10.17605/OSF.IO/2CHMU

Kotov, R., Gamez, W., Schmidt, F., \& Watson, D. (2010). Linking “big” personality traits to anxiety, depressive, and substance use disorders: A meta-analysis. Psychological Bulletin, 136, 768-821. https://doi.org/10.1037/a0020327

Kroencke, L., Geukes, K., Utesch, T., Kuper, N., \& Back, M. D. (2020). Neuroticism and emotional risk during the COVID-19 pandemic. Journal of Research in Personality, 89, 104038 .

Lange, J., Dalege, J., Borsboom, D., van Kleef, G. A., \& Fischer, A. H. (2020). Toward an integrative psychometric model of emotions. Perspectives in Psychological Science, 15, 444-468. https://doi.org/10.1177/1745691619895057

Lassale, C., Gaye, B., Hamer, M., Gale, C. R., \& Batty, G. D. (2020). Ethnic disparities in hospitalisation for COVID-19 in England: The role of socioeconomic factors, mental health, and inflammatory and pro-inflammatory factors in a community-based cohort study. Brain, behavior, and immunity, 88, 44-49.

LeViness, P., Bershad, C., Gorman, K., Braun, L., \& Murray, T. (2018). The Association for University and College Counseling Center Directors Annual Survey - Public Version 2018. Association for University and Counseling Center Directors. https://www.aucced.org/assets/documents/Survey/2018\%20AUCCCD\%20SurveyPublic-June\%2012-FINAL.pdf 
Li, X., Fu, P., Fan, C., Zhu, M., \& Li, M. (2021). COVID-19 Stress and Mental Health of Students in Locked-Down Colleges. International Journal of Environmental Research and Public Health, 18(2), 771.

Li, W., Wang, Z., Wang, G., Ip, P., Sun, X., Jiang, Y., \& Jiang, F. (2021). Socioeconomic inequality in child mental health during the COVID-19 pandemic: First evidence from China. Journal of Affective Disorders.

Lipson, S. K., Lattie, E. G., \& Eisenberg, D. (2019). Increased rates of mental health service utilization by US college students: 10-year population-level trends (20072017). Psychiatric Services, 70(1), 60-63.

Little, T. D. (2013). Longitudinal Structural Equation Modeling (Methodology in the Social Sciences). New York, NY: The Guilford Press.

Liu, X., Liu, J., \& Zhong, X. (2020). Psychological state of college students during COVID-19 epidemic. Available at SSRN 3552814.

Liu, C. H., Pinder-Amaker, S., Hahm, H. C., \& Chen, J. A. (2020). Priorities for addressing the impact of the COVID-19 pandemic on college student mental health. Journal of American College Health. https://doi.org/10.1080/07448481.2020.1803882

Liu, C. H., Stevens, C., Wong, S. H., Yasui, M., \& Chen, J. A. (2019). The prevalence and predictors of mental health diagnoses and suicide among US college students: Implications for addressing disparities in service use. Depression Anxiety, 36(1), 8-17. https://doi.org/10.1002/da.22830

Lucas, R. E. (2018). Exploring the associations between personality and subjective well-being. In E. Diener, S. Oishi, \& L. Tay (Eds.), Handbook of Well-Being (pp. 257-271). DEF Publishers. 
Lynch, A., Bastiampillai, T., \& Dhillon, R. (2020). Can COVID-19-related anxiety trigger a relapse of schizophrenia? Australian \& New Zealand Journal of Psychiatry, 0004867420954564.

Magson, N. R., Freeman, J. Y., Rapee, R. M., Richardson, C. E., Oar, E. L., \& Fardouly, J. (2021). Risk and protective factors for prospective changes in adolescent mental health during the COVID-19 pandemic. Journal of Youth and Adolescence, 50(1), 44-57.

Malouff, J. M., Thorsteinsson, E. B., \& Schutte, N. S. (2005). The relationship between the fivefactor model of personality and symptoms of clinical disorders: A meta-analysis. Journal of Psychopathology and Behavioral Assessment, 27, 101-114.

https://doi.org/10.1007/s10862-005-5384-y

McCrae, R. R., \& Costa, P. T. (1986). Personality, coping, and coping effectiveness in an adult sample. Journal of Personality, 54, 385-405.

McVicar, A. (2016). Scoping the common antecedents of job stress and job satisfaction for nurses (2000-2013) using the job demands-resources model of stress. Journal of Nursing Management, 24(2), E112-E136.

Merino, H., Senra, C., \& Ferreiro, F. (2016). Are worry and rumination specific pathways linking neuroticism and symptoms of anxiety and depression in patients with generalized anxiety disorder, major depressive disorder and mixed anxiety-depressive disorder? PLOS One, 11(5), e0156169. https://doi.org/10.1371/journal.pone.0156169

Moeller, J. (2015). A word on standardization in longitudinal studies: Don't. Frontiers in Psychology, 6(1389). https://doi.org/10.3389/fpsyg.2015.01389 
Moeller, J., Brackett, M., Ivcevic, Z., \& White, A. (2020). High school students' emotions: Discoveries from a large national survey and an experience sampling study. Learning and Instruction, 66. doi: 10.1016/j.learninstruc.2019.101301

Molenaar, P. C. (2008). On the implications of the classical ergodic theorems: Analysis of developmental processes has to focus on intra-individual variation. Developmental Psychobiology, 50(1), 60-69. https://doi.org/10.1002/dev.20262

National Institutes of Mental Health (NIMH). (2016). Mental health medications. https://www.nimh.nih.gov/health/topics/mental-health-medications/index.shtml National Sleep Foundation. (2006). Sleep in America. https:// sleepfoundation.org/sleep-pollsdata/sleep-in-america-poll/2006-teens-and-sleep.

Ni, M. Y., Yang, L., Leung, C. M. C., Li, N., Yao, X. I., Wang, Y., Leung, G. M., Cowling, B. J., \& Liao, Q. (2020). Mental health, risk factors, and social media use during the COVID19 epidemic and cordon sanitaire among the community and health professionals in Wuhan, China: Cross-sectional survey. JMIR Mental Health, 7(5), e19009. https://oi.org/10.2196/19009

Owens, J., \& Adolescent Sleep Working Group. (2014). Insufficient sleep in adolescents and young adults: An update on causes and consequences. Pediatrics, 134(3), e921-e932. https://doi.org/10.1542/peds.2014-1696

Owens, J. A., Belon, K., \& Moss, P. (2010). Impact of delaying school start time on adolescent sleep, mood, and behavior. Archives of Pediatrics and Adolescent Medicine, 164(7), 608614. https://doi.org/10.1001/archpediatrics.2010.96

Pérez-Rojas, A. E., Lockard, A. J., Bartholomew, T. T., Janis, R. A., Carney, D. M., Xiao, H., Youn, S. J., Scofield, B. E., Locke, B. D., Castonguay, L. G., \& Hayes, J. A. (2017). 
Presenting concerns in counseling centers: The view from clinicians on the ground. Psychological Services, 14(4), 416-427. https://doi.org/10.1037/ser0000122

Pfefferbaum, B., \& North, C. S. (2020). Mental health and the Covid-19 pandemic. New England Journal of Medicine, 383(6), 510-512.

Raj, S., Ghosh, D., Singh, T., Verma, S. K., \& Arya, Y. K. (2020). Theoretical mapping of suicidal risk factors during the CoViD-19 pandemic: a mini-review. Frontiers in Psychiatry, 11. https://doi.org/10.3389/fpsyt.2020.589614

Reitzle, M., \& Dietrich, J. (2019). From between-person statistics to within-person dynamics. Diskurs Kindheits- und Jugendforschung, 3-2019, 319-339. https://doi.org/10.3224/diskurs.v14i3.06

Sánchez-Teruel, D., Robles-Bello, M. A., \& Valencia-Naranjo, N. (2021). Do psychological strengths protect college students confined by COVID-19 to emotional distress? The role of gender. Personality and Individual Differences, 171, 110507.

Savitsky, B., Findling, Y., Ereli, A., \& Hendel, T. (2020a). Anxiety and coping strategies among nursing students during the Covid-19 pandemic. Nurse Education in Practice, 46, 102809.

Savitsky, B., Findling, Y., Ereli, A., \& Hendel, T. (2020b). Nursing Students in Crisis Mode: Fluctuations in Anxiety During the COVID-19-Related Lockdown. Nurse Educator. Schimmack, U., Oishi, S., Furr, R. M., \& Funder, D. C. (2004). Personality and Life Satisfaction: A Facet-Level Analysis. Personality and Social Psychology Bulletin, 30(8), 1062-1075, https://doi.org/10.1177/0146167204264292

Schönbrodt, F. D., \& Perugini, M. (2013). At what sample size do correlations stabilize? Journal of Research on Personality, 47, 609-612. https://doi.org/10.1016/j.jpp.2013.05.009 
Seppälä, E., Bradley, C., Moeller, J., Nandamudi, D., \& Brackett, M. A. (2020). Promoting mental health and well-being among university students: A randomized control trial of three well-being interventions. Frontiers in Psychiatry. https://doi.org/10.3389/fpsyt.2020.00590

Smidt, K. E., \& Suvak, M. K. (2015). A brief, but nuanced, review of emotional granularity and emotion differentiation research. Current Opinion in Psychology, 3, 48-51.

Smith, C. A., \& Ellsworth, P. C. (1985). Patterns of cognitive appraisal in emotion. Journal of Personality and Social Psychology, 48, 813-838. http://dx.doi.org/10.1037/00223514.48 .4 .813

Solberg, V. S., Valdez, J., \& Villarreal, P. (1994). Social support, stress, and Hispanic college adjustment: Test of a diathesis-stress model. Hispanic Journal of Behavioral Sciences, 16(3), 230-239.

Substance Abuse and Mental Health Services Administration (SAMHSA). (2017). 2017 National Survey on Drug Use and Health. https://www.nami.org/Learn-More/Mental-Health-Bythe-Numbers

Sun, S., Goldberg, S. B., Lin, D., Qiao, S., \& Operario, D. (2021). Psychiatric symptoms, risk, and protective factors among university students in quarantine during the COVID-19 pandemic in China. Globalization and Health, 17(1), 1-14.

Takarangi, M. K. T., Garry, M., \& Loftus, E. F. (2006). Dear diary, is plastic better than paper? I can't remember: Comment on Green, Rafaeli, Bolger, Shrout, and Reis (2006). Psychological Methods, 11, 119-122. https://doi.org/10.1037/1082-989X.11.1.119

Tang, W., Hu, T., Hu, B., Jin, C., Wang, G., Xie, C., ... \& Xu, J. (2020). Prevalence and correlates of PTSD and depressive symptoms one month after the outbreak of the 
COVID-19 epidemic in a sample of home-quarantined Chinese university students. Journal of affective disorders, 274, 1-7.

Tellegen, A., Watson, D., \& Clark, L. A. (1999). On the dimensional and hierarchical nature of affect. Psychological Science, 10, 297-303. http:// dx.doi.org/10.1111/1467-9280.00157

Romanowicz, M., Ehlers, S., Walker, D., Decker, P., Rundell, J., Shinozaki, G., ... \& Black, J. L. (2012). Testing a diathesis-stress model: potential genetic risk factors for development of distress in context of acute leukemia diagnosis and transplant. Psychosomatics, 53(5), $456-462$.

Rossi, R., Socci, V., Talevi, D., Mensi, S., Niolu, C., Pacitti, F., Di Marco, A., Rossi, A., Siracusano, A., \& Di Lorenzo, G. (2020). COVID-19 pandemic and lockdown measures impact on mental health among the general population in Italy. Frontiers in Psychiatry, 11, 790. https://doi.org/10.3389/fpsyt.2020.00790

Solberg, V. S., Valdez, J., \& Villarreal, P. (1994). Social support, stress, and Hispanic college adjustment: Test of a diathesis-stress model. Hispanic Journal of Behavioral Sciences, 16(3), 230-239.

Van der Aa, N., Overbeek, G., Engels, R. C., Scholte, R. H., Meerkerk, G. J., \& Van den Eijnden, R. J. (2009). Daily and compulsive internet use and well-being in adolescence: a diathesis-stress model based on big five personality traits. Journal of youth and adolescence, 38(6), 765 .

Vindegaard, N., \& Benros, M. E. (2020). COVID-19 pandemic and mental health consequences: Systematic review of the current evidence. Brain, Behavior, and Immunity, 89, 531-542.

Walters, K. S., Bulmer, S. M., Troiano, P. F., Obiaka, U., \& Bonhomme, R. (2018). Substance use, anxiety, and depressive symptoms among college students. Journal of Child \& 
Adolescent Substance Abuse, 27(2), 103-11.

https://doi.org/10.1080/1067828X.2017.1420507

Wendt, L. P., Wright, A. G., Pilkonis, P. A., Woods, W. C., Denissen, J. J. A., Kühnel, A., \& Zimmermann, J. (2020). Indicators of affect dynamics: Structure, reliability, and personality correlates. European Journal of Personality. Advance online publication. https://doi.org/10.1002/per.2277

Wong, M. C., Teoh, J. Y., Huang, J., \& Wong, S. H. (2020). The potential impact of vulnerability and coping capacity on the pandemic control of COVID-19. Advanced online publication. The Journal of Infection. https://doi.org/10.1007/s10654-020-00674-9

Xiong, J., Lipsitz, O., Nasri, F., Lui, L. M. W., Gill, H., Phan, L., Chen-Li, D., Iacobucci, M., Ho, R., Majeed, A., \& McIntyre, R. S. (2020). Impact of COVID-19 pandemic on mental health in the general population: A systematic review. Journal of Affective Disorders, 277, 55-64. https://doi.org/10.1016/j.jad.2020.08.001

Zainal Badri, S. K., \& Wan Mohd Yunus, W. M. A. (2021). The relationship between academic vs. family/personal role conflict and Malaysian students' psychological wellbeing during COVID-19 lockdown. Journal of Further and Higher Education, 1-13.

Zhang, K., Wu, S., Xu, Y., Cao, W., Goetz, T., \& Parks-Stamm, E. J. (2020). Adaptability promotes student engagement under COVID-19: The multiple mediating effects of academic emotion. Frontiers in Psychology, 11. 


\section{Figures}

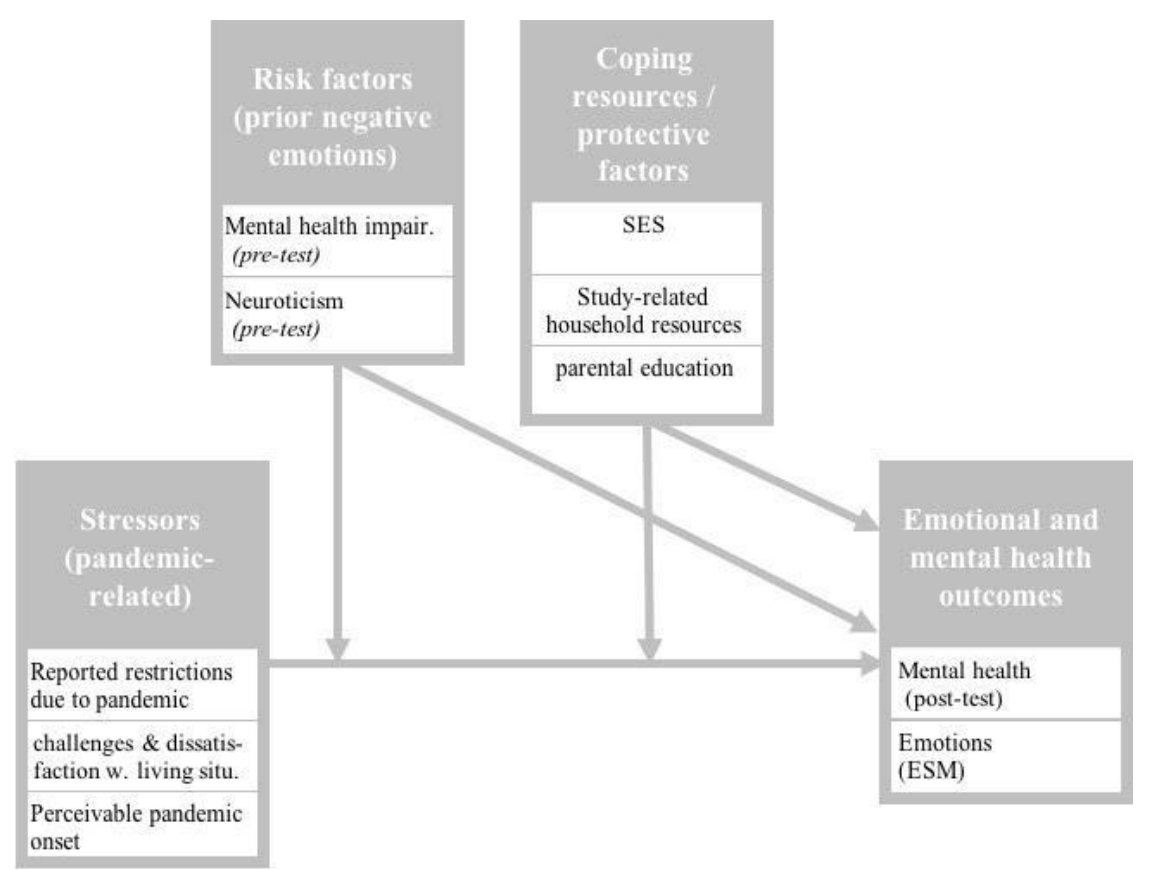

Figure 1: Our theoretical working model explaining how the COVID-19 pandemic may have affected college students' mental health 

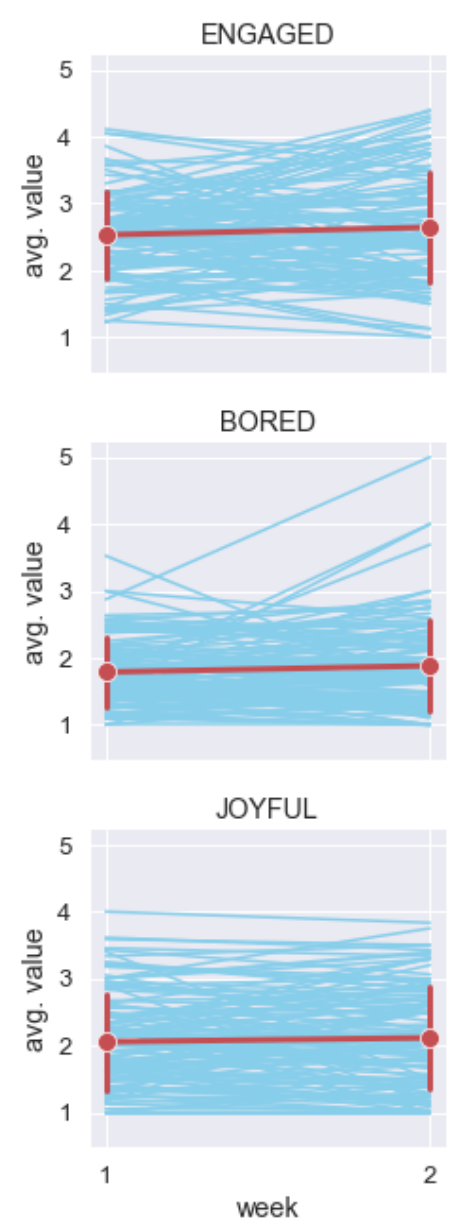

INTERESTED

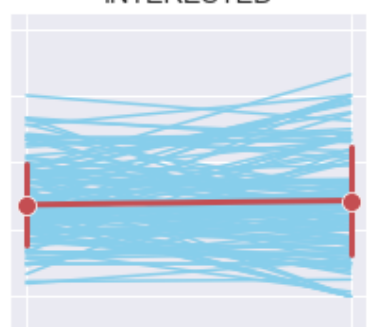

ANXIOUS

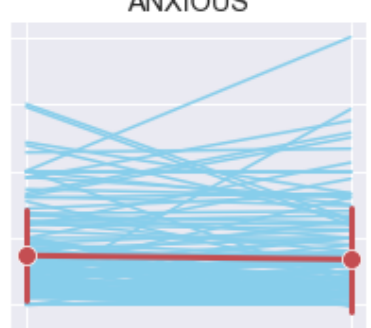

CONTENT

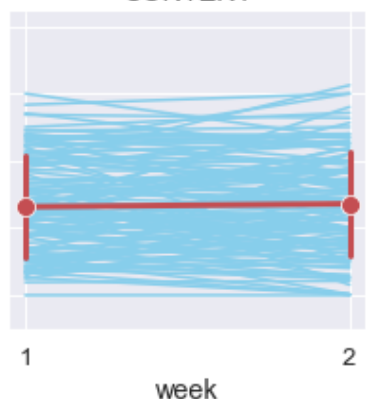

week
FRUSTRATED

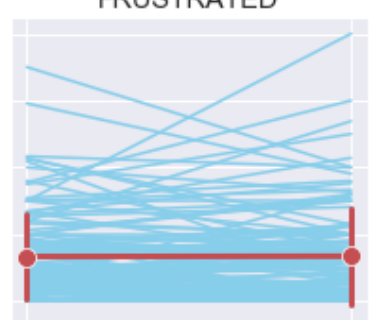

DEPRESSED

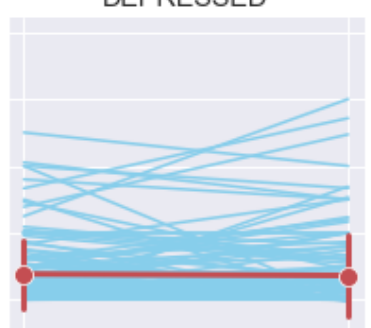

HOPELESS

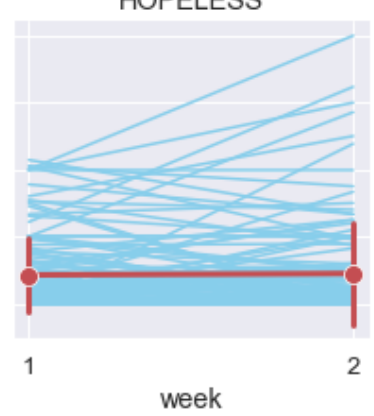

CONFUSED

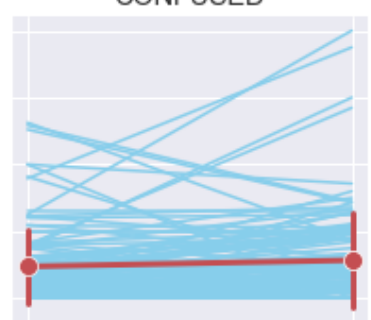

TIRED

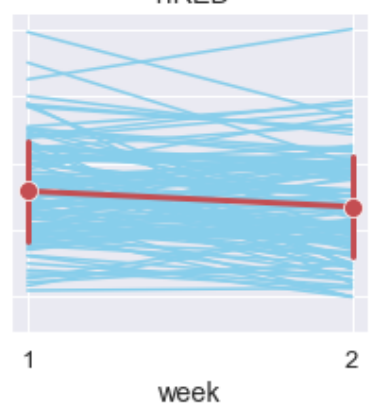

week

Figure 2: Distributions of the intra-individual trajectories for each person (blue lines) and on average (red line), with the red dots representing the average at each time point and the vertical red lines representing the standard deviations for each time point. 


\section{Tables}

\section{Table 1}

Slopes of emotions regressed on the binary measurement time point variable (Model 1)

\begin{tabular}{|c|c|c|c|c|c|c|c|c|}
\hline & Intercept $^{a}$ & Slope $e^{b}$ & $\begin{array}{c}p \text {-value } \\
\text { for the } \\
\text { slope }\end{array}$ & $\begin{array}{l}\text { Variance } \\
\text { emotion } \\
\text { (within- } \\
\text { level; } \\
\text { residual) }\end{array}$ & $\begin{array}{c}\text { Variance } \\
\text { emotion } \\
\text { intercept } \\
\text { (between- } \\
\text { level; } \\
\text { residual) }\end{array}$ & $\begin{array}{l}\text { Variance } \\
\text { slope } \\
\text { (between- } \\
\text { level; } \\
\text { residual) }\end{array}$ & $I C C$ & $\begin{array}{c}\text { Average } \\
\text { number } \\
\text { of valid } \\
\text { ESM } \\
\text { responses } \\
\text { per } \\
\text { person }\end{array}$ \\
\hline Interested & 4.085 & .185 & .196 & 4.814 & 1.331 & 1.427 & .211 & 21.170 \\
\hline Joyful & 3.383 & .078 & .463 & 4.002 & 2.127 & 0.534 & .338 & 21.121 \\
\hline Content & 3.939 & .116 & .335 & 3.864 & 2.328 & 0.889 & .352 & 21.142 \\
\hline Engaged & 4.422 & .362 & 0.014 & 5.035 & 1.462 & 1.478 & .231 & 21.149 \\
\hline Anxious & 2.660 & -.138 & .258 & 3.409 & 1.969 & 1.007 & .323 & 21.135 \\
\hline Frustrated & 2.483 & .006 & .952 & 3.669 & 1.441 & 0.374 & .271 & 21.092 \\
\hline Bored & 2.811 & .096 & .407 & 3.804 & 0.904 & 0.708 & .183 & 21.121 \\
\hline Confused & 2.057 & .171 & .151 & 2.847 & 1.151 & 0.890 & .252 & 21.170 \\
\hline Tired & 4.552 & -.528 & .000 & 4.488 & 2.262 & 1.404 & .280 & 21.106 \\
\hline Depressed & 1.858 & -.066 & .503 & 1.821 & 0.955 & 0.625 & .340 & 21.113 \\
\hline Hopeless & 1.944 & 0.035 & .765 & 2.089 & 1.245 & 1.005 & .369 & 21.071 \\
\hline
\end{tabular}

Note. $\mathrm{p}$-value is two-tailed here. ${ }^{\mathrm{a}}=$ Mean score across all ESM surveys at pre-pandemic onset; ${ }^{\mathrm{b}}=$ change from pre- $^{-}$ to post pandemic onset. 
Table 2

Emotions on prior mental health impairment (MHI)

\begin{tabular}{|c|c|c|c|c|c|c|c|c|c|c|c|}
\hline & anxiety & frustration & depressed & hopeless & tired & bored & confused & interested & engaged & joyful & content \\
\hline Est. Emotion intercept on MHI & .350 & .299 & .264 & .286 & .314 & .146 & .174 & -.129 & -.146 & -.209 & -.237 \\
\hline S.E. Emotion intercept on MHI & .081 & .073 & .050 & .061 & .089 & .060 & .072 & .076 & .077 & .083 & .085 \\
\hline $\mathrm{p}$ Emotion intercept on MHI & .000 & .000 & .000 & .000 & .000 & .008 & .008 & .045 & .029 & .006 & .003 \\
\hline Est. Emotion slope on MHI & -.015 & .013 & .077 & .090 & .041 & -.005 & .106 & -.105 & -.011 & -.071 & -.119 \\
\hline S.E. Emotion slope on MHI & .079 & .066 & .063 & .080 & .083 & .058 & .072 & .088 & .096 & .057 & .061 \\
\hline p Emotion slope on MHI & .422 & .423 & .110 & .130 & .312 & .463 & .070 & .117 & .454 & .104 & .027 \\
\hline Est. resid. corr. emotion with slope & -.460 & -.168 & -.170 & -.155 & -.812 & -.185 & -.360 & -.294 & -.177 & -.210 & -.460 \\
\hline S.E. resid. corr. emotion with slope & .239 & .195 & .162 & .167 & .255 & .223 & .255 & .209 & .227 & .158 & .190 \\
\hline p residual corr. emotion with slope & .027 & .195 & .147 & .177 & .001 & .203 & .079 & .079 & .218 & .091 & .008 \\
\hline Intercept emotion & 1.187 & 1.224 & 0.741 & 0.737 & 3.233 & 2.194 & 1.322 & 4.630 & 5.044 & 4.258 & 4.932 \\
\hline Intercept slope & -0.063 & -0.054 & -0.375 & -0.327 & -0.692 & 0.121 & -0.267 & 0.611 & 0.395 & 0.371 & 0.610 \\
\hline Residual variance emotion & 1.588 & 1.170 & 0.723 & 0.990 & 1.963 & 0.851 & 1.048 & 1.293 & 1.420 & 2.008 & 2.188 \\
\hline Residual variance slope & 1.015 & 0.401 & 0.617 & 1.006 & 1.390 & 0.709 & 0.880 & 1.394 & 1.472 & 0.523 & 0.837 \\
\hline
\end{tabular}

Note. Est. = estimate; S.E. $=$ standard error. All estimates are unstandardized. p-value is one-tailed. 
Table 3

Emotions on trait emotional instability

anxiety frustration depressed hopeless tired bored confused interested engaged joyful content

\begin{tabular}{llllllllllll}
\hline Est. Emotion intercept on trait emo. insta. & $\mathbf{. 1 5 8}$ & $\mathbf{. 0 9 4}$ & $\mathbf{. 0 8 7}$ & $\mathbf{. 1 1 5}$ & $\mathbf{. 1 6 9}$ & .038 & .032 & $\mathbf{- . 0 8 8}$ & $\mathbf{- . 1 0 2}$ & $\mathbf{- . 1 8 5}$ & $\mathbf{- . 1 9 8}$ \\
S.E. Emotion intercept on trait emo. insta & $\mathbf{. 0 5 0}$ & $\mathbf{. 0 4 9}$ & $\mathbf{. 0 3 8}$ & $\mathbf{. 0 4 1}$ & $\mathbf{. 0 6 2}$ & .042 & .046 & $\mathbf{. 0 5 2}$ & $\mathbf{. 0 5 0}$ & $\mathbf{. 0 6 5}$ & $\mathbf{. 0 6 7}$ \\
p Emotion intercept on trait emo. insta. & $\mathbf{. 0 0 1}$ & $\mathbf{. 0 2 8}$ & $\mathbf{. 0 1 2}$ & $\mathbf{. 0 0 3}$ & $\mathbf{. 0 0 4}$ & .185 & .244 & $\mathbf{. 0 4 5}$ & $\mathbf{. 0 2 1}$ & $\mathbf{. 0 0 3}$ & $\mathbf{. 0 0 2}$ \\
Est. Emotion slope on trait emo. insta. & $\mathbf{- . 0 9 2}$ & -.005 & -.020 & -.050 & -.016 & -.025 & $\mathbf{. 0 8 7}$ & -.090 & -.042 & -.058 & -.077 \\
S.E. Emotion slope on trait emo. insta. & $\mathbf{. 0 4 5}$ & .034 & .033 & .031 & .062 & .048 & $\mathbf{. 0 4 3}$ & .065 & .066 & .047 & .055 \\
p Emotion slope on trait emo. insta. & $\mathbf{. 0 1 9}$ & .437 & .272 & .055 & .399 & .303 & $\mathbf{. 0 2 2}$ & .083 & .263 & .107 & .080 \\
Est. residual corr. emotion with slope & -.399 & -.130 & -.106 & -.039 & -.760 & -.175 & -.319 & -.297 & -.201 & -.211 & -.435 \\
S.E. residual corr. emotion with slope & .274 & .215 & .180 & .196 & .249 & .225 & .260 & .203 & .223 & .155 & .183 \\
p residual correlation emotion with slope & .073 & .273 & .279 & .422 & .001 & .218 & .110 & .072 & .184 & .087 & .009 \\
Intercept emotion & 1.669 & 1.893 & 1.313 & 1.222 & 3.492 & 2.573 & 1.855 & 4.641 & 5.067 & 4.541 & 5.183 \\
Intercept slope & 0.440 & 0.043 & 0.062 & 0.347 & -0.424 & 0.252 & -0.371 & 0.738 & 0.618 & 0.437 & 0.594 \\
Residual variance emotion & 1.852 & 1.395 & 0.921 & 1.181 & 2.143 & 0.897 & 1.145 & 1.295 & 1.423 & 1.966 & 2.132 \\
Residual variance slope & & & & & & & & & & & \\
\hline
\end{tabular}

Note. Est. = estimate; S.E. = standard error. All estimates are unstandardized. p-value is one-tailed here. Please note: We measured instability (neuroticism), but use the reversed term emotional stability throughout the manuscript, because it is better known in the literature. 
Table 4

Emotions on Socioeconomic status (ladder question)

anxiety frustration depressed hopeless tired bored confused interested engaged joyful content

\begin{tabular}{|c|c|c|c|c|c|c|c|c|c|c|c|}
\hline Est. Emotion intercept on SES & .034 & -.049 & -.016 & -.015 & .050 & .008 & -.016 & .076 & .074 & .066 & .227 \\
\hline S.E. Emotion intercept on SES & .065 & .055 & .050 & .051 & .083 & .056 & .041 & .067 & .069 & .090 & .081 \\
\hline p Emotion intercept on SES & .303 & .186 & .375 & .380 & .275 & .446 & .346 & .129 & .140 & .230 & .003 \\
\hline Est. Emotion slope on SES & -.075 & -.074 & -.044 & -.041 & -.068 & -.089 & -.030 & .073 & .002 & .151 & .061 \\
\hline S.E. Emotion slope on SES & .060 & .048 & .052 & .058 & .092 & .059 & .058 & .094 & .108 & .064 & .080 \\
\hline p Emotion slope on SES & .106 & .064 & .195 & .239 & .229 & .066 & .299 & .219 & .492 & .009 & .224 \\
\hline Est. residual corr. emotion with slope & -.467 & -.142 & -.116 & -.071 & -.762 & -.168 & -.291 & -.280 & -.180 & -.179 & -.414 \\
\hline S.E. residual corr. emotion with slope & .300 & .219 & .182 & .198 & .265 & .228 & .259 & .202 & .226 & .163 & .181 \\
\hline p residual corr. emotion with slope & .060 & .258 & .262 & .360 & .002 & .232 & .130 & .084 & .213 & .136 & .012 \\
\hline Intercept emotion & 2.491 & 2.732 & 1.939 & 2.022 & 4.302 & 2.774 & 2.139 & 3.703 & 4.049 & 3.046 & 2.790 \\
\hline Intercept slope & 0.239 & 0.377 & 0.158 & 0.242 & -0.185 & 0.542 & 0.324 & -0.182 & 0.350 & -0.687 & -0.188 \\
\hline Residual variance emotion & 1.967 & 1.435 & 0.955 & 1.245 & 2.258 & 0.903 & 1.150 & 1.317 & 1.449 & 2.112 & 2.189 \\
\hline Residual variance slope & 0.988 & 0.355 & 0.618 & 0.999 & 1.391 & 0.671 & 0.886 & 1.408 & 1.478 & 0.438 & 0.863 \\
\hline
\end{tabular}

Note. Est. = estimate; S.E. = standard error. All estimates are unstandardized. p-value is one-tailed here. 
Table 5

Emotions on parents' education

anxiety frustration depressed hopeless tired bored confused interested engaged joyful content

\begin{tabular}{lccccccccccc}
\hline Est. emot. intercept on parents' educ. & $\mathbf{. 1 7 6}$ & $\mathbf{. 1 2 5}$ & $\mathbf{. 1 3 4}$ & $\mathbf{. 1 4 3}$ & $\mathbf{. 1 4 2}$ & .052 & .062 & .015 & .016 & -.046 & .056 \\
S.E. emot. intercept on parents' educ. & $\mathbf{. 0 4 1}$ & $\mathbf{. 0 3 9}$ & $\mathbf{. 0 2 7}$ & $\mathbf{. 0 3 4}$ & $\mathbf{. 0 5 3}$ & .038 & .042 & .048 & .051 & .065 & .066 \\
p emotion intercept on parents' educ. & $\mathbf{. 0 0 0}$ & $\mathbf{. 0 0 1}$ & $\mathbf{. 0 0 0}$ & $\mathbf{. 0 0 0}$ & $\mathbf{. 0 0 4}$ & .086 & .073 & .374 & .377 & .240 & .196 \\
Est. emotion slope on parents' educ. & -.020 & -.012 & -.016 & -.011 & .032 & $\mathbf{. 0 8 7}$ & $\mathbf{. 0 8 9}$ & .020 & .029 & .007 & -.021 \\
S.E. emotion slope on parents' educ. & .041 & .034 & .027 & .034 & .050 & $\mathbf{. 0 3 5}$ & $\mathbf{. 0 4 1}$ & .050 & .064 & .043 & .046 \\
p emotion slope on parents' educ. & .311 & .359 & .279 & .377 & .263 & $\mathbf{. 0 0 6}$ & $\mathbf{. 0 1 5}$ & .344 & .323 & .431 & .322 \\
Est. residual corr. emotion with slope & -.438 & -.118 & -.093 & -.050 & -.824 & -.210 & -.323 & -.263 & -.178 & -.161 & -.365 \\
S.E. residual corr. emotion with slope & .278 & .203 & .168 & .182 & .272 & .226 & .250 & .204 & .233 & .167 & .192 \\
p residual corr. emotion with slope & .058 & .281 & .291 & .391 & .001 & .177 & .099 & .099 & .222 & .167 & .029 \\
Intercept emotion & & & & & & & & & & \\
Intercept slope & 1.473 & 1.646 & 0.946 & 0.977 & 3.601 & 2.457 & 1.640 & 3.980 & 4.314 & 3.692 & 3.557 \\
Residual variance emotion & -0.002 & 0.086 & 0.042 & 0.109 & -0.750 & -0.506 & -0.442 & 0.049 & 0.162 & 0.028 & 0.261 \\
Residual variance slope & 1.718 & 1.317 & 0.805 & 1.077 & 2.111 & 0.882 & 1.123 & 1.329 & 1.460 & 2.110 & 2.303 \\
\hline
\end{tabular}

Note. Est. = estimate; S.E. = standard error. All estimates are unstandardized. p-value is one-tailed here. 


\section{Table 6}

Resource 1: Do you have the study materials (e.g., textbooks) you need for your courses in this quarter?

\begin{tabular}{|c|c|c|c|c|c|c|c|c|c|c|c|}
\hline & anxiety & frustration & depressed & hopeless & tired & bored & confused & interested & engaged & joyful & content \\
\hline Est. Emotion intercept on resource 1 & -.015 & -.094 & -.072 & -.097 & -.136 & -.067 & -.097 & -.035 & .026 & .014 & -.015 \\
\hline S.E. Emotion intercept on resource 1 & .057 & .050 & .055 & .057 & .066 & .049 & .053 & .060 & .069 & .064 & .066 \\
\hline p Emotion intercept on resource 1 & .400 & .029 & .097 & .046 & .020 & .085 & .033 & .280 & .357 & .412 & .410 \\
\hline Est. Emotion slope on resource 1 & -.211 & -.152 & -.133 & -.147 & -.079 & -.117 & -.132 & .015 & -.051 & .083 & .104 \\
\hline S.E. Emotion slope on resource 1 & .079 & .058 & .058 & .076 & .053 & .072 & .079 & .057 & .067 & .045 & .050 \\
\hline p Emotion slope on resource 1 & .004 & .005 & .012 & .027 & .068 & .052 & .049 & .396 & .226 & .033 & .020 \\
\hline Est. residual corr. emotion with slope & -.460 & -.225 & -.138 & -.144 & -.777 & -.230 & -.346 & -.255 & -.174 & -.152 & -.352 \\
\hline S.E. residual corr. emotion with slope & .296 & .206 & .184 & .202 & .255 & .226 & .244 & .208 & .229 & .162 & .190 \\
\hline p residual corr. emotion with slope & .060 & .137 & .227 & .237 & .001 & .155 & .078 & .110 & .224 & .175 & .032 \\
\hline Intercept emotion & 2.776 & 3.241 & 2.429 & 2.714 & 5.639 & 3.346 & 2.837 & 4.372 & 4.222 & 3.272 & 4.064 \\
\hline Intercept slope & 1.580 & 1.236 & 1.022 & 1.235 & 0.121 & 1.045 & 1.246 & 0.056 & 0.765 & -0.606 & -0.730 \\
\hline Residual variance emotion & 1.971 & 1.405 & 0.927 & 1.198 & 2.182 & 0.882 & 1.101 & 1.332 & 1.472 & 2.122 & 2.349 \\
\hline Residual variance slope & 0.804 & 0.283 & 0.547 & 0.935 & 1.327 & 0.638 & 0.809 & 1.428 & 1.468 & 0.489 & 0.825 \\
\hline
\end{tabular}

Note. Est. $=$ estimate; S.E. $=$ standard error. All estimates are unstandardized. p-value is one-tailed here. 


\section{Table 7}

Resource 2: Do you have a stable internet connection?

\begin{tabular}{|c|c|c|c|c|c|c|c|c|c|c|c|}
\hline & anxiety & frustration & depressed & hopeless & tired & bored & confused & interested & engaged & joyful & content \\
\hline Est. Emotion intercept on resource 2 & -.056 & -.097 & -.054 & -.092 & -.231 & -.044 & -.102 & -.051 & -.050 & .010 & .024 \\
\hline S.E. Emotion intercept on resource 2 & .051 & .049 & .043 & .045 & .070 & .048 & .049 & .061 & .065 & .071 & .075 \\
\hline p Emotion intercept on resource 2 & .135 & .024 & .107 & .020 & .001 & .179 & .019 & .202 & .219 & .446 & .374 \\
\hline Est. Emotion slope on resource 2 & -.032 & -.060 & -.036 & .006 & .047 & -.124 & -.049 & .116 & .072 & .154 & .089 \\
\hline S.E. Emotion slope on resource 2 & .049 & .041 & .038 & .053 & .062 & .046 & .051 & .060 & .074 & .052 & .059 \\
\hline p Emotion slope on resource 2 & .258 & .073 & .170 & .453 & .223 & .004 & .172 & .027 & .165 & .002 & .066 \\
\hline Est. residual corr. emotion with slope & -.480 & -.185 & -.120 & -.074 & -.721 & -.227 & -.315 & -.223 & -.143 & -.163 & -.381 \\
\hline S.E. residual corr. emotion with slope & .299 & .220 & .184 & .201 & .252 & .235 & .255 & .212 & .225 & .156 & .197 \\
\hline p residual corr. emotion with slope & .054 & .200 & .257 & .356 & .002 & .167 & .108 & .147 & .263 & .148 & .027 \\
\hline Intercept emotion & 3.116 & 3.268 & 2.287 & 2.682 & 6.414 & 3.160 & 2.878 & 4.498 & 4.837 & 3.309 & 3.747 \\
\hline Intercept slope & 0.129 & 0.494 & 0.239 & -0.006 & -0.903 & 1.116 & 0.577 & -0.775 & -0.242 & -1.199 & -0.619 \\
\hline Residual variance emotion & 1.954 & 1.406 & 0.943 & 1.214 & 2.048 & 0.897 & 1.105 & 1.330 & 1.456 & 2.128 & 2.348 \\
\hline Residual variance slope & 1.004 & 0.383 & 0.629 & 1.028 & 1.386 & 0.667 & 0.886 & 1.362 & 1.429 & 0.422 & 0.859 \\
\hline
\end{tabular}

Note. Est. = estimate; S.E. = standard error. All estimates are unstandardized. p-value is one-tailed here. 
Table 8

Resource 3: Do you have Computer(s) or other devices to work on your course-related tasks?

\begin{tabular}{|c|c|c|c|c|c|c|c|c|c|c|c|}
\hline & anxiety & frustration & depressed & hopeless & tired & bored & confused & interested & engaged & joyful & content \\
\hline Est. Emotion intercept on resource 3 & -.123 & -.177 & -.077 & -.122 & -.228 & -.174 & -.182 & -.034 & .081 & .099 & .082 \\
\hline S.E. Emotion intercept on resource 3 & .096 & .082 & .063 & .070 & .088 & .064 & .105 & .085 & .065 & .087 & .089 \\
\hline p Emotion intercept on resource 3 & .101 & .015 & .109 & .041 & .005 & .004 & .042 & .346 & .107 & .125 & .180 \\
\hline Est. Emotion slope on resource 3 & .144 & .088 & -.018 & .055 & .117 & .007 & .113 & .065 & -.055 & .052 & .093 \\
\hline S.E. Emotion slope on resource 3 & .070 & .064 & .049 & .063 & .062 & .058 & .095 & .079 & .083 & .085 & .072 \\
\hline p Emotion slope on resource 3 & .021 & .086 & .357 & .191 & .031 & .453 & .117 & .204 & .254 & .270 & .098 \\
\hline Est. residual corr. emotion with slope & -.438 & -.111 & -.114 & -.062 & -.706 & -.184 & -.241 & -.245 & -.166 & -.173 & -.391 \\
\hline S.E. residual corr. emotion with slope & .281 & .216 & .180 & .201 & .266 & .238 & .230 & .201 & .227 & .160 & .197 \\
\hline p residual corr. emotion with slope & .060 & .304 & .263 & .380 & .004 & .220 & .147 & .111 & .232 & .141 & .024 \\
\hline Intercept emotion & 3.800 & 4.135 & 2.572 & 3.071 & 6.664 & 4.417 & 3.746 & 4.402 & 3.678 & 2.462 & 3.183 \\
\hline Intercept slope & -1.477 & -0.832 & 0.107 & -0.472 & -1.613 & 0.032 & -0.882 & -0.432 & 0.865 & -0.415 & -0.749 \\
\hline Residual variance emotion & 1.933 & 1.373 & 0.941 & 1.211 & 2.142 & 0.826 & 1.069 & 1.336 & 1.454 & 2.102 & 2.334 \\
\hline Residual variance slope & 0.962 & 0.372 & 0.632 & 1.023 & 1.371 & 0.711 & 0.869 & 1.407 & 1.474 & 0.522 & 0.858 \\
\hline
\end{tabular}

Note. Est. = estimate; S.E. = standard error. All estimates are unstandardized. p-value is one-tailed here. 


\section{Table 9}

Resource 4: Do you have a study place that allows you to focus on your coursework this quarter?

\begin{tabular}{|c|c|c|c|c|c|c|c|c|c|c|c|}
\hline & anxiety & frustration & depressed & hopeless & tired & bored & confused & interested & engaged & joyful & content \\
\hline Est. Emotion intercept on resource 4 & -.027 & -.093 & -.040 & -.057 & -.091 & -.046 & -.047 & .024 & .038 & .122 & .130 \\
\hline S.E. Emotion intercept on resource 4 & .046 & .038 & .029 & .031 & .050 & .033 & .040 & .041 & .041 & .047 & .050 \\
\hline p Emotion intercept on resource 4 & .277 & .008 & .080 & .034 & .036 & .081 & .119 & .274 & .178 & .005 & .005 \\
\hline Est. Emotion slope on resource 4 & -.084 & -.079 & -.106 & -.093 & -.056 & -.045 & -.109 & .023 & .004 & .019 & .039 \\
\hline S.E. Emotion slope on resource 4 & .059 & .045 & .036 & .048 & .045 & .044 & .050 & .054 & .053 & .038 & .044 \\
\hline p Emotion slope on resource 4 & .077 & .039 & .002 & .028 & .106 & .155 & .014 & .336 & .469 & .309 & .185 \\
\hline Est. residual corr. emotion with slope & -.506 & -.221 & -.150 & -.132 & -.805 & -.208 & -.349 & -.253 & -.171 & -.173 & -.394 \\
\hline S.E. residual corr. emotion with slope & .304 & .203 & .175 & .190 & .266 & .227 & .256 & .204 & .227 & .153 & .191 \\
\hline p residual corr. emotion with slope & .048 & .138 & .196 & .244 & .002 & .180 & .086 & .107 & .226 & .129 & .020 \\
\hline Intercept emotion & 2.832 & 3.073 & 2.107 & 2.297 & 5.123 & 3.095 & 2.355 & 3.934 & 4.189 & 2.611 & 3.115 \\
\hline Intercept slope & 0.422 & 0.520 & 0.638 & 0.651 & -0.149 & 0.394 & 0.895 & 0.025 & 0.322 & -0.055 & -0.148 \\
\hline Residual variance emotion & 1.962 & 1.378 & 0.940 & 1.219 & 2.186 & 0.890 & 1.131 & 1.334 & 1.462 & 2.014 & 2.223 \\
\hline Residual variance slope & 0.960 & 0.348 & 0.526 & 0.950 & 1.368 & 0.693 & 0.811 & 1.419 & 1.473 & 0.525 & 0.857 \\
\hline
\end{tabular}

Note. Est. = estimate; S.E. = standard error. All estimates are unstandardized. p-value is one-tailed here. 


\section{Table 10}

How changes in emotions relate to changes in mental health impairment (A MHI; Model 4)

\begin{tabular}{|c|c|c|c|c|c|c|c|c|c|c|c|}
\hline & anxiety & frustration & depressed & hopeless & tired & bored & confused & interested & engaged & joyful & content \\
\hline Est. Emotion intercept on $\Delta \mathrm{MHI}$ & .050 & -.010 & .086 & .082 & .108 & .036 & .039 & -.048 & -.051 & -.101 & .057 \\
\hline S.E. Emotion intercept on $\Delta \mathrm{MHI}$ & .090 & .090 & .065 & .078 & .094 & .062 & .078 & .086 & .095 & .107 & .115 \\
\hline $\mathrm{p}$ Emotion intercept on $\Delta \mathrm{MHI}$ & .289 & .455 & .093 & .147 & .126 & .283 & .309 & .286 & .294 & .174 & .309 \\
\hline Est. Emotion slope on $\Delta \mathrm{MHI}$ & .241 & .234 & .144 & .176 & .030 & .179 & .179 & .189 & .052 & -.009 & -.007 \\
\hline S.E. Emotion slope on $\Delta \mathrm{MHI}$ & .099 & .085 & .083 & .105 & .106 & .082 & .103 & .111 & .115 & .069 & .074 \\
\hline $\mathrm{p}$ Emotion slope on $\Delta \mathrm{MHI}$ & .008 & .003 & .043 & .047 & .387 & .015 & .041 & .045 & .326 & .449 & .465 \\
\hline Est. resid. corr. emotion with slope & -.482 & -.086 & -.130 & -.090 & -.768 & -.184 & -.273 & -.261 & -.177 & -.162 & -.374 \\
\hline S.E. resid. corr. emotion with slope & .269 & .183 & .175 & .184 & .264 & .227 & .247 & .200 & .233 & .161 & .191 \\
\hline p residual corr. emotion with slope & .037 & .320 & .228 & .314 & .002 & .208 & .135 & .096 & .224 & .157 & .026 \\
\hline Intercept emotion & 2.389 & 2.533 & 1.392 & 1.500 & 3.969 & 2.618 & 1.846 & 4.343 & 4.697 & 3.924 & 3.629 \\
\hline Intercept slope & -1.402 & -1.225 & -0.820 & -0.889 & -0.684 & -0.847 & -0.769 & -0.807 & 0.089 & 0.123 & 0.153 \\
\hline Residual variance emotion & 1.966 & 1.436 & 0.937 & 1.225 & 2.240 & 0.898 & 1.145 & 1.322 & 1.455 & 2.100 & 2.321 \\
\hline Residual variance slope & 0.891 & 0.249 & 0.586 & 0.940 & 1.403 & 0.652 & 0.808 & 1.357 & 1.473 & 0.534 & 0.884 \\
\hline
\end{tabular}

Note. Est. $=$ estimate; S.E. $=$ standard error. All estimates are unstandardized. p-value is one-tailed. 


\section{Appendices / Supplemental online materials}

S-1: $\quad$ All Mplus outputs (open code) will be shared on our project page on the Open Science Framework after the blinded review. Example input for the models underlying Table 1 and 2 are provided here.

S-2: $\quad$ Detailed description of the surveying schedules (incl. Figure S-3)

S-3: $\quad$ Reasons for examining granular emotions rather than higher-order factor models S-4: $\quad$ ESM survey

Figure S-5: ESM surveying schedule for the three groups. Only the weeks from February 24th to March 3rd, 2020 (time 1) and the weeks from March 30th to April 10th (time 2) were used for the analyses in this study.

Figure S-6: Violin plots showing ESM emotion scores by SES ladder step with each student's average across time represented as one dot (jitter). 


\section{S-1: Mplus input}

Title: Model 1 Anxious (corresponds to TABLE 1 in the manuscript);

Data:

FILE IS "ESM.dat";

VARIABLE:

Names $=\quad$ anxious Week ESM_ID esm1k101_r esm1k102_r esm1k103_r esm1k104_r esm1k105_r esm1k106_r esm1k107_r esm1k108_r esm1k109_r esm1k110_r;

Usevar $=$ anxious_r Week;

MISSING ARE ALL $(-99,99)$;

Cluster = ESM_ID;

Within = Week;

ANALYSIS:

type $=$ twolevel random;

Estimator $=$ MLR;

MODEL:

\%WITHIN\%

Slope_ChangeEmotion | anxious_r ON Week;

\%between $\%$

anxious_r with Slope_ChangeEmotion;

output: sampstat; 
Title: Model 2.1 Mental Health Impairment \& Anxious (corresponds to TABLE 2 in the manuscript);

Data:

FILE IS "ESM.dat";

\section{VARIABLE:}

Names $=\quad$ anxious Week ESM_ID esm1k101_r esm1k102_r esm1k103_r esm1k104_r esm1k105_r esm1k106_r esm1k107_r esm1k108_r esm1k109_r esm1k110_r;

Usevar =Anxious_r Week MentalHealth_T1;

MISSING ARE ALL (-99, 99);

Cluster = ESM_ID;

Within $=$ Week;

Between $=$ MentalHealth_T1;

Define:

MentalHealth_T1 $=($

esm1k101_r+

esm1k102-r+

esm1k103_r+

esm1k104-r+

esm1k105_r+

esm1k106_r+

esm1k107- r+

esm1k108_r+

esm1k109-r+

esm1k110_r)/10;

\section{ANALYSIS:}

type $=$ twolevel random;

Estimator $=$ MLR;

\section{MODEL:}

\%within \%

Slope_ChangeEmotion | Anxious_r ON week;

$\%$ between $\%$

Anxious_r ON MentalHealth_T1; ! Predicting the intercept by the level-2 predictor

Slope_ChangeEmotion ON MentalHealth_T1; ! Predicting the slope by the level-2 predictor

Anxious_r with Slope_ChangeEmotion; ! Residual correlation between random intercept and random slope

MentalHealth_T1;

output: sampstat; 


\section{S-2: Detailed description of the surveying schedules}

Since this was originally intended to be a pilot study comparing different surveying schedules, there were three groups with different schedules, which are described in Figure 3. Group A ( $n=48$ students) received 7 surveys each week during the weeks of February 24 - April 10, 2020. Surveys only occurred on weekdays but were sent out randomly at any time point between 8 a.m. on Monday and 8 p.m. on Friday. Students had 30 minutes to respond to the surveys. Group B ( $n=52$ students) received surveys on the weekdays of February 24-28 and March 30-April 5, 2020. Five surveys were sent out per day, one in each of five 2.5-hour intervals (8:00 a.m.-10:30 a.m., 10:30 a.m.-1:00 p.m., 1:00 p.m.-3:00 p.m., 3:00 p.m.-5:30 p.m., 5:30 p.m.-8:00 p.m.).

Surveys were sent out at random times within each time interval and participants had 30 minutes to respond to the surveys. Group C ( $n=41$ students) received surveys on the weekdays of March 2-6 and April 6-10, 2020. The Group C surveys were scheduled in the same way as Group B surveys. Once the questionnaire had been opened, it timed out and became unavailable if participants did not complete the full questionnaire within 30 minutes. 


\section{S-3: Reasons for examining granular emotions rather than higher-order factor models}

The eleven emotions examined as outcomes in this study are kept as separate outcomes, rather than being collapsed into composite scores or higher-order factors, for the following reasons:

First, previous literature on granular emotions suggests that the particular, unique content of one emotion is not entirety exchangeable with an emotion sharing the same valence, arousal level, or approach motivation (e.g., Kashdan, Barrett, \& McKnight, 2015; Smidt, \& Suvak, 2015). Although emotions do exhibit systematic covariance if they share one of these dimensions (e.g., if both emotions are of positive valence), they are hardly exchangeable indicators of the same latent variable. Instead, the content of an emotion often hints at its causes, at the unique feelings that a person may experience when endorsing this emotion item predicting unique outcomes. Many years of research on the factor structure of emotions (e.g., Cacioppo \& Berntson, 1994; Davidson, 1998; Diener \& Emmons, 1984; Frijda, 1986; Russell \& Carroll, 1999; Smith \& Ellsworth, 1985; Tellegen et al., 1999) have therefore cumulated in emphasizing the insightful granularity of emotions and the potential insights that can be gained from keeping emotions on that granular level, rather than collapsing them into higher-order factor models (e.g., Lange et al., 2020).

Second, factor analyses on similar ESM emotion measures supported models with unrestricted co-variance above factor models (e.g., Moeller, Brackett, Ivcevic, \& White, 2020). Moreover, if factor models were considered, the factor structure would look different on the within- and the between-level. Furthermore, this study does not have a sufficient sample size to estimate the factor structure reliably on the between-level in addition to all the other parameters that needed to be estimated. 
Third, this longitudinal study employs a time lag design between pre- and post-test weeks of ESM data collection. Thus, a factor model would necessitate time-invariance to examine changes in the eventual emotion factors.

Fourth, the relationships of a construct (here: an emotion) with predictors and outcomes is generally often larger and easier to interpret on the level of specific facets than on the level of higher-order factors (Armstrong \& Anthoney, 2009; Beauducel et al., 2007; Bipp et al., 2008; Schimmack et al., 2004).

For all these reasons, we treated each emotion as a separate outcome in separate regression models. A further reason for this decision were the rather small sample sizes of both situations and particularly of individuals, which made it necessary to limit the number of parameters to be estimated in a model. 


\section{S-4: ESM Survey}

1) Were you on the UCI campus when you were beeped? Yes / No

2) Where were you when you were beeped?

a. My home/apartment/dorm

b. A friend's/family member's home

c. A study place (e.g., library, classroom, research lab)

d. My workplace

e. Athletic facility/ field (e.g., gym, court)

f. A place to eat (e.g., restaurant, food court)

g. Recreational location (e.g., mall, movie theater, etc.)

h. Locations for basic needs (e.g., bank, grocery store, dentist's office, post office, etc.)

i. On-the-move (e.g., driving from one location to another)

j. Outdoors

3) What was the main activity you were doing when you were beeped? Please describe in 1 to 5 words.

4) With whom were you doing the activity you just described? Please check all that apply.

a. No one

b. Close friend(s)

c. Classmate/other student(s)

d. Roommate/dormmate

e. Significant other/romantic partner/spouse

f. Family member

g. Professor/course instructor/TA

h. University staff (e.g. counselor, acad. Advisor)

i. Unknown person

All emotions were measured on a scale from $1=$ Not at all, $2=$ A little, $3=$ Somewhat, $4=$ More than some, 5 = Extremely.

5) How engaged did you feel when you were beeped?

6) How interested did you feel when you were beeped?

7) How frustrated did you feel when you were beeped?

8) How confused did you feel when you were beeped?

9) How bored did you feel when you were beeped?

10) How anxious did you feel when you were beeped?

11) How depressed did you feel when you were beeped?

12) How tired did you feel when you were beeped?

13) How joyful did you feel when you were beeped?

14) How content did you feel when you were beeped?

15) How hopeless did you feel when you were beeped? 


\begin{tabular}{|c|c|c|c|c|c|c|c|c|c|c|}
\hline Week & $2 / 3-2 / 7$ & 2/10-2/14 & 2/17-2/21 & 2/24-2/28 & $3 / 2-3 / 6$ & $3 / 9-3 / 13$ & $3 / 16-3 / 20$ & 3/23-3/27 & $3 / 30-4 / 3$ & $4 / 6-4 / 10$ \\
\hline & $\begin{array}{r}\text { recruit } \\
\text { inst } \\
\text { backgro }\end{array}$ & $\begin{array}{l}\text { ent app } \\
\text { lation, } \\
\text { nd survey }\end{array}$ & & & & $\begin{array}{l}\text { instructio } \\
\text { n winter } \\
2020 \\
\text { ends }\end{array}$ & $\begin{array}{l}\text { final } \\
\text { exams }\end{array}$ & break & \begin{tabular}{|l|} 
instruction \\
spring \\
2020 \\
begins
\end{tabular} & \\
\hline $\begin{array}{l}\text { Group A, } 100 \\
\text { students }\end{array}$ & & & & \begin{tabular}{|c|}
50 \\
random \\
beeps, \\
sent out \\
between \\
Mondays \\
and \\
Fridays \\
\\
Data of \\
this week \\
used for \\
this article \\
\end{tabular} & $\begin{array}{c}\text { Data of } \\
\text { this week } \\
\text { used for } \\
\text { this article }\end{array}$ & $\begin{array}{c}\text { Data of } \\
\text { this week } \\
\text { gathered } \\
\text { but not } \\
\text { used in } \\
\text { the } \\
\text { analyses } \\
\text { for this } \\
\text { article }\end{array}$ & \begin{tabular}{|c} 
Data of \\
this week \\
gathered \\
but not \\
used in \\
the \\
analyses \\
for this \\
article \\
\end{tabular} & \begin{tabular}{|} 
Data of \\
this week \\
gathered \\
but not \\
used in \\
the \\
analyses \\
for this \\
article \\
\end{tabular} & $\begin{array}{c}\text { Data of } \\
\text { this week } \\
\text { used for } \\
\text { this article }\end{array}$ & $\begin{array}{c}\text { Data of } \\
\text { this week } \\
\text { used for } \\
\text { this article } \\
\end{array}$ \\
\hline $\begin{array}{l}\text { Group B, } 50 \\
\text { students }\end{array}$ & & & & $\begin{array}{l}25 \text { beeps, } \\
5 \text { per day }\end{array}$ & & & & & $\begin{array}{l}25 \text { beeps, } \\
5 \text { per day }\end{array}$ & \\
\hline $\begin{array}{l}\text { Group C, } 50 \\
\text { students }\end{array}$ & & & & & $\begin{array}{l}25 \text { beeps, } \\
5 \text { per day }\end{array}$ & & & & & $\begin{array}{l}25 \text { beeps, } \\
5 \text { per day }\end{array}$ \\
\hline
\end{tabular}

Figure S-5: ESM surveying schedule for the three groups. Only the weeks from February 24th to March 3rd, 2020 (time 1) and the weeks from March 30th to April 10th (time 2) were used for the analyses in this study. 

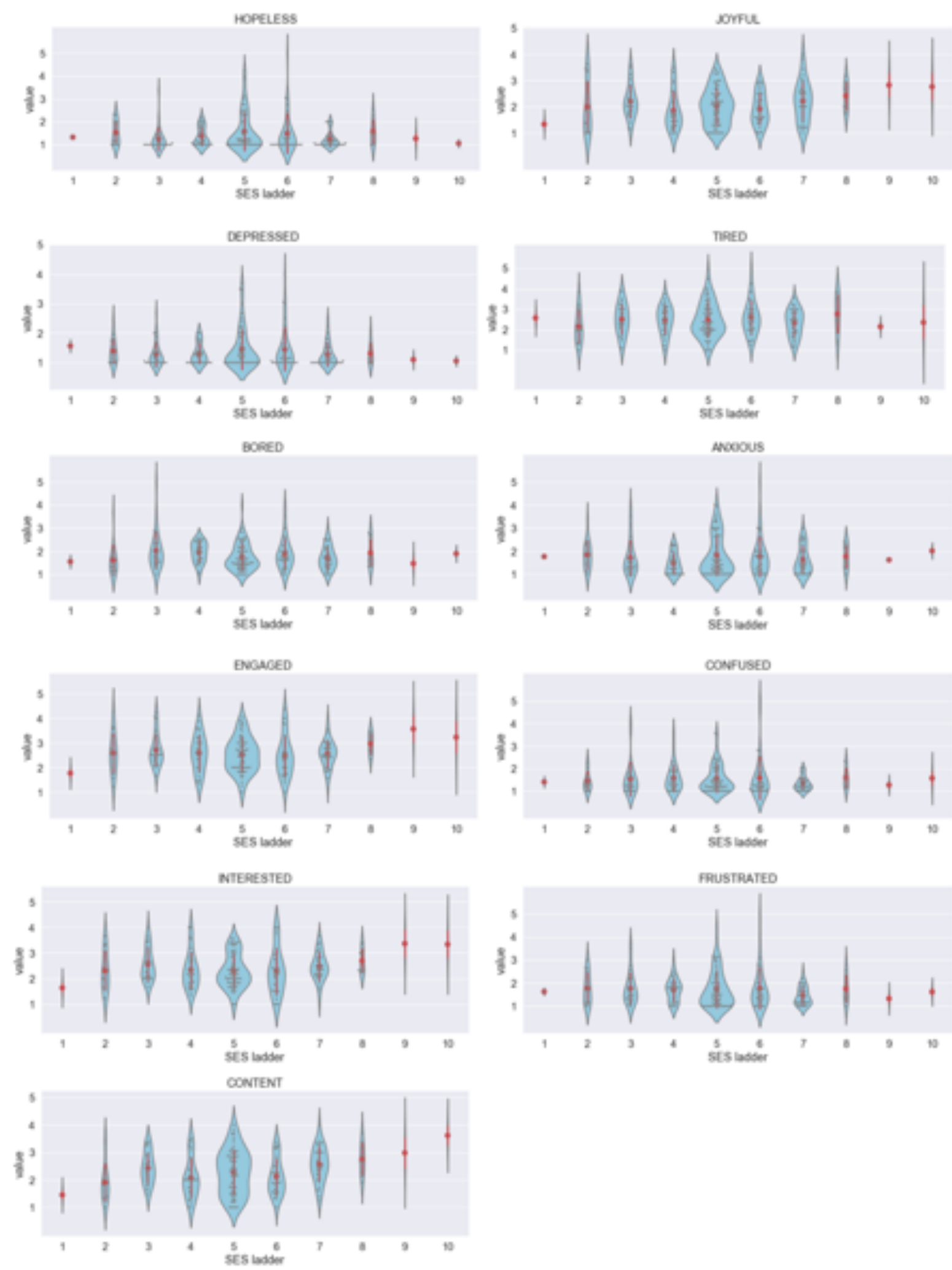

Figure S-6: Violin plots showing ESM emotion scores by SES ladder step with each student's person-level average across time points represented as one dot (jitter) 